\title{
LA REVOLUCIÓN ELÉCTRICA EN AMÉRICA LATINA: UNA RECONSTRUCCIÓN CUANTITATIVA DEL PROCESO DE ELECTRIFICACIÓN HASTA 1930*
}

XAVIER TAFUNELL

Universitat Pompeu Fabra $^{\text {a }}$

The electric revolution in Latin America: A quantitative approach to the electrification process until 1930

\begin{abstract}
Latin America participated in the electric revolution which profoundly transformed the most developed Western economies between 1880 and 1930. The qualitative empirical evidence shows that Latin American electrification began with little delay compared to those economies. This article provides new quantitative evidence consisting of annual series about a reliable indicator of the degree of electrification of the Latin American nations. The database built shows that towards 1930 electricity consumption per inhabitant in Latin America was far below that of most advanced economies, and only Latin American leaders in the electrification process had reached power consumption levels similar to the European late comers. Unlike other newly industrializing economies, the region was not able to quickly incorporate new technology to overcome their backwardness.
\end{abstract}

Keywords: Latin American growth, comparative development, technological progress, electricity, general purpose technologies

JEL code: N76, N16, O33, L94

* Received 17 December 2010. Accepted 28 June 2011. Este trabajo ha contado con el apoyo financiero del MICIIN (proyecto ECO2010-15882). Agradezco los comentarios recibidos por diversos participantes en el II Congreso de CLADHE, celebrado en México en febrero de 2010, donde se presentó una versión preliminar del trabajo, así como los valiosos comentarios de tres evaluadores anónimos del artículo.

a Departamento de Economía y Empresa, Ramón Trías Fargas, 25-27, Barcelona. xavier. tafunell@upf.edu 


\section{RESUMEN}

América Latina participó de la revolución eléctrica que transformó profundamente las economías occidentales más desarrolladas entre 1880 y 1930. La evidencia empírica de carácter cualitativo muestra que Latinoamérica comenzó a electrificarse con poco retraso respecto a esas economías. Este artículo aporta nueva evidencia cuantitativa consistente en series anuales sobre un indicador fiable del grado de electrificación de las naciones latinoamericanas. De la base de datos construida se desprende que hacia 1930 el consumo de electricidad por habitante de la región estaba muy por debajo del de las economías más avanzadas, y sólo los países latinoamericanos líderes en el proceso de electrificación habían alcanzado niveles de consumo eléctrico similares a los de algunos países europeos periféricos. A diferencia de otras economías de industrialización tardía, la región fue incapaz de incorporar con rapidez la nueva tecnología para superar su situación de atraso.

Palabras clave: Crecimiento de América Latina, Desarrollo comparado, Progreso tecnológico, Electricidad, Tecnologías de aplicación general

\section{INTRODUCCIÓN}

Uno de los lugares comunes historiográficos que concita mayor consenso es el papel clave desempeñado por la tecnología en el proceso de crecimiento económico. Obras seminales sobre el proceso histórico de desarrollo de la tecnología y la industria moderna como las de Landes (1969), Rosenberg (1982) y Mokyr (1990) han proporcionado fundamentos empíricos y analíticos muy sólidos a esta idea. En los últimos años ha habido un renovado interés por el tema por parte de los economistas, a partir de que Bresnahan y Trajtenberg (1995) acuñaran el concepto general purpose technologies para referirse a aquellas tecnologías cuyo impacto sobre el crecimiento económico es muy grande y perdurable ${ }^{1}$. Los economistas se han sentido atraídos por la cuestión al buscar una hipótesis explicativa a la llamada paradoja de la productividad, esto es, la aparente ausencia de una aceleración en el crecimiento de la productividad del trabajo y la multifactorial (PTF) tras un largo período de difusión de las tecnologías de la información y la comunicación (TIC) soportadas por los equipos electrónicos de procesamiento de datos ${ }^{2}$. Los trabajos teóricos

1 Sobre las características y propiedades del concepto, Lipsey et al. (1998). Sobre los conceptos afines pero no idénticos a general purpose technology manejados por economistas e historiadores económicos, tales como macroinvenciones, paradigmas tecno-económicos y revoluciones tecnológicas, Lipsey et al. (2005, pp. 371-84).

${ }^{2}$ La paradoja abrió el apetito intelectual de los economistas a finales de la década de 1980 y en los primeros años 1990, y así quedó reflejado en trabajos como los de Baily y Gordon (1988) y David (1990; 1991). Transcurridos unos años la paradoja fue disolviéndose, al constatarse que las TIC 
atribuyen esa prolongada pausa de productividad, empleando la expresión de David y Wright (2003), al hecho de que para aprovechar el enorme potencial de ganancias de productividad que encierra la nueva tecnología de aplicación general es necesario desarrollar una amplia variedad de innovaciones tecnológicas y organizativas en múltiples actividades, lo que dificulta la coordinación y compromete la propia existencia de incentivos apropiados para desarrollar la nueva tecnología ${ }^{3}$. Los trabajos empíricos efectuados por los historiadores económicos han seguido la vía de explorar los paralelismos entre los procesos de difusión de las TIC y de la electricidad, o, para decirlo en las palabras del más afamado de los autores que se han dedicado al tema, las similitudes entre la revolución de la dinamo y la del computador ${ }^{4}$. De tales trabajos se desprenden un par de lecciones importantes. Una es que llevó décadas que las innovaciones fundamentales tuvieran una amplia difusión en los países más industrializados. Otra es que hasta que no se alcanzó ese nivel de uso muy extendido de la electricidad, esta no dio lugar a una aceleración en la tasa de crecimiento de la productividad del trabajo y el capital ${ }^{5}$.

Los estudios realizados sobre el proceso de electrificación abarcan tan sólo las economías más desarrolladas, al menos aquellos que son de naturaleza comparativa $^{6}$. Debido a ello, seguimos sin tener respuesta a una importante cuestión: ¿la electricidad se difundió con más rapidez en las economías menos desarrolladas, aprovechando su acceso más tardío a la nueva tecnología? Los argumentos a favor de una respuesta afirmativa se sustentarían en la hipótesis gerschenkroniana de las ventajas del atraso, en este caso, materializadas en el ahorro de los costes de desarrollo y maduración de las innovaciones complementarias, y, asimismo, en no tener que amortizar el capital invertido (sunk costs) en la tecnología precedente (máquina de vapor) ni tener que desprenderse del capital social acumulado en el manejo de esa tecnología (path dependence). David y Wright (2003) defienden este punto de vista, pero únicamente basándose en la experiencia de Japón, en contraposición a la de Estados Unidos y Reino Unido. Ristuccia y Solomou (2002) sostienen la tesis contraria, a partir de los mismos casos, más el de Alemania. La hipótesis

\footnotetext{
(F'note continued)

finalmente sí tenían un impacto claro y positivo sobre la PTF (Oliner y Sichel, 2000) y sobre la productividad del trabajo (Oulton, 2002), cuando menos en el caso de EEUU y Reino Unido.

3 El desarrollo teórico que sustenta la hipótesis del lento ritmo de avance de las tecnologías de aplicación general se encuentra ya en la proposición original de Bresnahan y Trjtenberg (1995), y de forma más extensa en Helpman y Trajtenberg (1998a; 1998b). Una visión actualizada de estos planteamientos en Lipsey et al. (2005, pp. 385-496).

4 David (1990). Una comparación rigurosa y sistemática entre los procesos de difusión de ambas tecnologías en Jovanovic y Rousseau (2005).

5 Crafts (2004) ha llegado a conclusiones parecidas respecto al impacto que tuvo la máquina de vapor en la economía británica.

${ }^{6}$ V. Byatt (1979), Hughes (1983), Schurr et al. (1990) y Segreto (1993). Ciertamente, Hausman, Hertner y Wilkins (2008) analizan cómo se desenvolvió la electrificación en los cinco continentes, pero no realizan un estudio detallado a escala nacional.
} 
gerschenkroniana está también respaldada por el caso de Finlandia (Jalava y Pohjola, 2008). Es obvio que resulta necesario investigar cómo se desenvolvió el proceso de electrificación en muchas otras economías.

El propósito del presente trabajo es descubrir cómo se propagó la electricidad en América Latina durante la época en que acaeció la revolución eléctrica que transformó profundamente la vida económica y social en el mundo occidental, en el medio siglo que siguió a 1880. Esto no ha sido objeto de investigación histórica rigurosa, y su pertinencia es clara: en esta época los países latinoamericanos constituían una fracción sustancial del concierto de naciones políticamente independientes existentes en el mundo. El historiador económico Rippy (1947, pp. 208-16) sostuvo la tesis que Latinoamérica asistió con puntualidad al nacimiento de la revolución eléctrica pero fue incapaz de seguir el ritmo marcado por las naciones industrializadas. Avanzó con tanta lentitud, según él, que al llegar la Gran Depresión había acumulado un retraso de unos treinta años con respecto a Estados Unidos y los países europeos más desarrollados. No obstante, su interpretación no se fundamenta en datos cuantitativos, y de hecho tiene un carácter muy superficial. Lo mismo cabe decir del otro estudio existente, que tenga noticia, sobre el conjunto de la región. Al igual que Rippy, Carson (1946) sostiene que ésta comenzó a electrificarse temprano. Pero, a juicio del segundo autor, la introducción de la electricidad vino inducida por el interés de los inversores europeos en promover los tranvías eléctricos, con lo que se descuidó la difusión de la electricidad más allá de su uso restringido como fuente de iluminación. Las interpretaciones de ambos autores siguen intactas porque, a pesar de haber transcurrido seis décadas desde que fueron formuladas ningún historiador económico se ha interesado en someterlas a contrastación empírica. Este artículo afronta este reto. Consiste, en esencia, en una reconstrucción cuantitativa del proceso de electrificación en todas las repúblicas latinoamericanas (salvo Panamá), con el fin de situar el mismo en perspectiva comparada.

El artículo está estructurado del siguiente modo. Tras esta primera sección introductoria, en la segunda sección se lleva a cabo una aproximación al conocimiento de los inicios de la era de la electricidad en Latinoamérica en sus diversas aplicaciones básicas —iluminación, tracción y fuerza mecánica一, valiéndose de las fuentes nacionales publicadas que están a nuestro alcance. De una evidencia tan fragmentaria y parcial como ésta se desprende que el arranque de la electrificación fue relativamente precoz en la mayoría de naciones de la región. Pero en la difusión de la nueva tecnología se detecta una diversidad muy marcada de trayectorias: mientras las economías, más avanzadas, del Cono Sur siguen la senda, e incluso el ritmo, de las economías industriales europeas, en los países latinoamericanos atrasados - la mayoríala electrificación parece mantenerse durante décadas en estado incipiente. La tercera parte del trabajo contiene una contribución empírica novedosa que aspira a definir de manera precisa cómo se desenvolvió el proceso de 
electrificación en los países latinoamericanos. En ausencia de estadísticas referentes a la capacidad, la producción o el consumo de electricidad, la reconstrucción cuantitativa se sustenta en los datos de importación de material eléctrico; para ser más exactos, en la exportación del mismo a los diversos países latinoamericanos por parte de las economías más industrializadas, empleando la misma metodología utilizada por Tafunell (2009a y 2009b), la cual ha probado ser válida a la vista de los resultados obtenidos. Las series elaboradas han sido confrontadas con la información compilada sobre capacidad instalada al final del período, lo que ha permitido refinar el indicador de producción eléctrica que se entrega en el artículo. Las series en cuestión confirman lo que podíamos inferir, o más bien intuir, de la aproximación realizada en el segundo apartado: en algunas economías latinoamericanas la adopción de la electricidad debió seguir una pauta semejante a la de algunas economías europeas periféricas, en tanto que en la mayoría de economías latinoamericanas avanzó con suma lentitud. La cuarta sección está dedicada a un sencillo ejercicio de comparación de los niveles de electrificación alcanzados por los países latinoamericanos con respecto a los de otros países, teniendo en cuenta sus respectivos niveles de PIB per cápita. La comparación sugiere que la hipótesis gerschenkroniana no es aplicable a la región. El artículo se cierra con unas breves consideraciones finales a modo de conclusión.

\section{LOS ORÍGENES DE LA ERA DE LA ELECTRICIDAD EN AMÉRICA LATINA}

Como es sabido, las innovaciones tecnológicas clave de la revolución eléctrica aparecieron en los dos decenios comprendidos entre 1871 y 1891, el lapso que media entre la invención de la dinamo de Gramme y el primer sistema de transmisión a larga distancia del fluido eléctrico con corriente alterna de alta tensión. Entre medio, en Estados Unidos y en Europa, aparecieron grandes novedades tecnológicas, tales como: la lámpara de luz incandescente (1879); la locomotora eléctrica (1879); la primera central eléctrica que soportaba un sistema centralizado de generación y distribución de corriente eléctrica (1881); el tranvía eléctrico (1881); la turbina de vapor (1884); el motor de inducción de Tesla (1888), alimentado con corriente alterna, y, de forma prácticamente simultánea, el convertidor rotatorio que permite convertir corriente alterna en continua y viceversa ${ }^{7}$. Ahora bien, como no dejan de recordar los historiadores de la tecnología, una cosa es la invención y la innovación y otra bien distinta su difusión.

En las economías industrializadas, la secuencia de la aplicación de la electricidad transitó de la iluminación a la tracción (en el transporte urbano),

7 Bright (1949), Passer (1953), Siemens (1957), Machefert-Tassin, Nouvion y Woimant (1980), Singer et al. (1980), Hughes (1983), Weiher y Goetzeler (1984) y Carlson (1991). 
y en tercer lugar a la provisión de fuerza industrial ${ }^{8}$. Solamente cuando se construyeron centrales eléctricas dotadas de potentes generadores que consintieron una drástica rebaja de las tarifas gracias a que sacaban provecho de las economías de escala y de red, se difundió masivamente la electricidad, lo cual no ocurrió hasta comienzos del siglo $\mathrm{XX}^{9}$. En los lugares donde había corrientes de agua extremadamente abundantes se produjo un brote electrificador temprano, anterior al del aprovechamiento generalizado de la electricidad por parte de la industria, consistente en la aplicación electrolítica y electrotérmica ${ }^{10}$.

En América Latina el desarrollo eléctrico inicial parece haber seguido otros derroteros, o, para ser más exactos, la secuencia de aplicación ha sido distinta según países. Algunos, los más avanzados económicamente, no se apartaron del patrón de los países innovadores. También tendieron a ajustarse a él las ciudades más importantes de las economías no tan desarrolladas. En cambio, en los países más atrasados el alumbrado eléctrico vino de la mano de la tracción (tranvías eléctricos) o de la fuerza mecánica instalada en establecimientos mineros o fabriles, o bien, alternativamente, durante mucho tiempo el uso de la electricidad prácticamente quedó restringido a dar luz en calles y casas. Finalmente, en los núcleos urbanos de algunas economías escasamente desarrolladas pero dinámicas todas las aplicaciones se introdujeron a la vez. En cuanto a las electroindustrias, su presencia en la región fue mínima, al no venir dictada tanto por las posibilidades de explotar grandes recursos hidráulicos como por la conveniencia de extraer el metal de masivos recursos mineros ${ }^{11}$.

Naturalmente, todo cuanto acaba de decirse debería ser probado. No obstante, la base documental para hacerlo es muy débil, porque nos enfrentamos a una carencia casi absoluta de datos cuantitativos sobre la producción y el uso de la electricidad en la mayoría de naciones latinoamericanas durante esa época, e incluso hasta mediados del siglo $\mathrm{XX}^{12}$. Es más, son también muy escasas y dispersas las informaciones de carácter cualitativo sobre la implantación y el desarrollo inicial de las empresas eléctricas establecidas en muchas partes de la región, por no hablar de los autoproductores, respecto a los cuales nuestra ignorancia es todavía mayor, pese a que en ciertos países generaban una cantidad de energía superior, o no muy inferior, a la entregada al público por las compañías eléctricas. En estas condiciones, en los párrafos siguientes haré un simple esbozo de los

${ }^{8}$ David y Wright (1999).

9 David (1990, pp. 325-6); Hausman, Hertner y Wilkins (2008, pp. 9-19).

${ }^{10}$ Bartolomé (2007, p. 14).

11 En realidad, la única actividad relevante fue la industria de producción de cobre mediante electrólisis en Chile. En 1929 esta actividad (minería y metalurgia) absorbía el 62 por cien de la capacidad de generación eléctrica de todo el país, v. Dirección General de Estadística (1931, pp. 15-6).

12 CEPAL (1956); Naciones Unidas (1962). 
momentos inaugurales de la electricidad, en sus distintos usos, en las repúblicas latinoamericanas, sin ningún afán de ofrecer una visión completa sobre el tema. El conocimiento que podemos extraer de una aproximación de este tenor es limitado pero sirve para ilustrar algunas características básicas de la electrificación en América Latina durante el período pionero.

\subsection{La iluminación eléctrica}

En la segunda mitad de la década de 1870 en las ciudades latinoamericanas más dinámicas y receptivas a las novedades tecnológicas que iban apareciendo en Europa y Estados Unidos tuvieron lugar las primeras demostraciones públicas del funcionamiento de la luz eléctrica mediante la instalación en algún lugar céntrico de un circuito de lámparas de arco eléctrico conectado a una dinamo. Así sucedió en La Habana en 1877, en Brasil en 1879, en México en 1880, y Caracas en $1883^{13}$. Esas exhibiciones públicas de las cualidades de la luz eléctrica acaecieron casi al mismo tiempo que en Francia e Inglaterra ${ }^{14}$. La inauguración de los primeros sistemas de generación eléctrica de servicio público con redes de distribución más o menos extensas se produjo con un retraso algo mayor, aunque generalmente menor a un decenio. Londres y Nueva York contaron con los primeros sistemas eléctricos públicos del mundo, en 1881, mientras que en Latinoamérica, entraron en funcionamiento por primera vez en las capitales de los diversos países, o, en ocasiones, alguna otra ciudad, en los años siguientes: Brasil y Chile en 1883; Costa Rica en 1884; Argentina y Perú en 1886; México y Uruguay en 1887; Bolivia y Venezuela en 1888; Cuba y Panamá en 1889; Colombia en 1890; y Ecuador en 1897. En cuanto a los más rezagados, Paraguay no contó con servicio público eléctrico hasta 1913, y no tengo noticia de que Haití lo tuviera antes de $1912^{15}$.

Es interesante reparar en que entre las ciudades pioneras figuran capitales de países muy atrasados, como por ejemplo la capital boliviana, que se enorgulleció de ser la tercera ciudad en Sudamérica en contar con servicio público eléctrico, apenas un año más tarde que Buenos Aires y uno por delante de La Habana ${ }^{16}$. Esto nos sugiere que la fecha de apertura del

13 Para Cuba, Mota (1982, pp. 8-14) y Altshuler (1998); para Brasil, A energia elétrica (1977, p. 34); para México, De la Garza (1994, p. 17) y Liehr y Leidenberger (2006, pp. 272-3); en el caso de Caracas, Frank (1999, p. 245). Para los países sudamericanos en general, v. CIER (1989).

14 Bright (1949, p. 29).

15 V. Villalobos (1990), para Chile; Rohrmoser (1986), para Costa Rica; Galarza (1941, pp. 16-8), para México; Altshuler y González (1997, pp. 209-23) y Altshuler (1998), para Cuba; De la Pedraja (1985, p. 100) para Panamá; Velasco y Valeria (2007, p. 4), para Bolivia; Camilo et al. (1999, p. 76) para Colombia; Frank (1999, p. 246) para Venezuela; y Halsey (1918, p. 312) y Herken (1984, pp. 23, 32 y 106) acerca de Paraguay. Respecto a los países sudamericanos en general, v. CIER (1989). Acerca de Haití, v. Boletín de la Unión Panamericana (1912, febrero, p. 207).

16 Velasco y Valeria (2007, p. 4). 
alumbrado público y privado con luz eléctrica no puede tomarse como un indicador del nivel de desarrollo inicial de la electricidad, en términos comparativos. Distinto es el caso opuesto, el de aquellos países en que los primeros sistemas eléctricos públicos se establecieron entrado el siglo XX. No es nada casual que así ocurriera en Haití y Paraguay, tratándose de las economías más subdesarrolladas de la región.

Sin embargo, es preciso tener en cuenta que la inexistencia de centrales eléctricas de servicio público no equivalía necesariamente a carecer por completo de luz eléctrica. No era infrecuente que empresas mineras y manufactureras produjeran electricidad para su propio consumo y que tuvieran una capacidad excedentaria, con lo que comercializaban la energía sobrante distribuyéndola por las poblaciones vecinas. Esto fue bastante común allí donde la minería tenía una gran importancia, como en Bolivia y México. En estos países, la electricidad no sólo se introdujo por primera vez de la mano de autoproductores industriales, sino que además la aportación de éstos adquirió notable relevancia antes, e incluso tiempo después, de que arraigaran las primeras empresas de servicio público ${ }^{17}$.

El momento inaugural de la electrificación nada nos dice sobre la intensidad de su avance posterior. En la mayoría de lugares, lo hizo, al parecer, con suma lentitud. Pero en otros emergieron muy pronto sistemas completos (generación-transmisión-distribución) que imprimieron un ritmo acelerado de difusión de la electricidad. Esto ocurrió en algunos de los principales núcleos o conurbaciones urbanas de la región de tamaño suficiente para sacar provecho de las economías de escala y de red: Buenos Aires, Río de Janeiro, São Paulo, Montevideo y la ciudad de México. Las áreas metropolitanas de las dos grandes ciudades brasileñas y de la capital mexicana disfrutaron de un desarrollo eléctrico muy intensivo, que además acaeció al mismo tiempo que en Europa, gracias a que atrajeron a uno de los grupos empresariales internacionales con mayor capacidad técnica y financiera para sacar partido al potencial hidroeléctrico que atesoran zonas montañosas próximas a las mencionadas conurbaciones ${ }^{18}$. Añadamos que el crecimiento acelerado no quedó circunscrito a aquellas áreas urbanas donde existían condiciones especialmente adecuadas para seguir el modelo

17 Respecto a México, Galarza (1941, pp. 9-14) y De La Garza (1994, pp. 18-21); para Bolivia, CIER (1989, pp. 145-6). El modelo de electrificación boliviano es distintivo, por extremo, al de otros países con fuerte peso de la minería, como Chile, México y Perú. Todavía en 1930 correspondía a la minería el 83 por cien de la electricidad consumida en Bolivia.

${ }^{18}$ La historia de las empresas canadienses Brazilian Traction, Light and Power Company y Mexican Light and Power Company, y del papel, fundamental, que desempeñaron en la electrificación de Brasil y México es bien conocida gracias a los trabajos de Armstrong y Nelles (1988) y McDowall (1988). Los activos conjuntos de ambos holdings, creados por los mismos promotores, bajo el liderazgo de F. Pearson, sobrepasaban levemente a los activos de las empresas eléctricas latinoamericanas pertenecientes al grupo de American and Foreign Power Co. Ningún otro grupo de empresas eléctricas existente en el mundo en los años 1930 tenía unas dimensiones comparables a estos tres holdings, según Hausman, Hertner y Wilkins (2008, p. 218). 
hidráulico; también lo fue en ciertas urbes que recurrieron al modelo térmico (carbón), como Buenos Aires y Montevideo.

\subsection{La tracción eléctrica}

El tranvía eléctrico significó la primera aplicación a gran escala de la electricidad como fuerza motriz ${ }^{19}$. En 1888 en Estados Unidos se produjo la innovación —el sistema Sprague- que marcó una ruptura tecnológica y dio paso a una asombrosa expansión del nuevo medio de transporte: la electrificación de los tranvías, en EEUU, se completó en poco más de una déc$\operatorname{ada}^{20}$. Las naciones europeas más industrializadas avanzaron con menos ímpetu. En Gran Bretaña y Francia el despegue tuvo lugar en 1895 y el proceso de electrificación todavía no pudo darse por finalizado en 1913, mientras que en Alemania avanzó a mayor ritmo, situándose en un punto intermedio entre Estados Unidos y las otras potencias europeas, según Byatt (1979, pp. 28-32). En ambos lados del Atlántico, la difusión del tranvía eléctrico potenció grandemente el crecimiento de las aglomeraciones urbanas y contribuyó al auge industrial que se vivió en esa época.

En Latinoamérica se reprodujo el mismo fenómeno con un leve retraso, y seguramente con menor intensidad. En Brasil el primer tranvía eléctrico circuló en fecha tan temprana como 1892, en Rio de Janeiro, si bien el país no mantuvo su precocidad en otras ciudades ${ }^{21}$. En Argentina, la primera línea de tranvía eléctrico entró en servicio en Córdoba en 1898, según Rippy (1947, p. 209). Al año siguiente se inició en Chile la tracción eléctrica ${ }^{22}$. En 1900 se inauguraba la primera línea de los tranvías eléctricos en Buenos Aires, en la ciudad de México y en la bahía de La Habana ${ }^{23}$. Durante la primera década del siglo XX el nuevo medio de transporte hizo su aparición en las restantes grandes urbes del continente, así como en muchas otras ciudades del mismo, tal como demuestra Rippy (1947, p. 209). Pero lo que debemos preguntarnos es: ¿cuánto tiempo llevó la conversión al sistema de tracción eléctrico? En el caso argentino, la electrificación de los tranvías podía darse prácticamente por finalizada ya en $1914^{24}$. No obstante, esto fue, con toda seguridad, algo excepcional. Incluso Montevideo, en cabeza del

\footnotetext{
19 La electrificación de los ferrocarriles no urbanos avanzó muy despacio en los propios países más industrializados. Duffy (2003: 16-27).

${ }^{20}$ McKay (1976, pp. 47-51); Machefert, Nouvion y Woimant (1980, pp. 51-8).

21 En São Paulo se inauguró en 1900, mientras que en las capitales de los estados norteños no lo hizo hasta la tercera década del siglo. A energia elétrica (1977: 35 y 45).

22 CIER (1989, p. 210).

23 Halsey (1918, pp. 483-4); De La Garza (1994, p. 18); Liehr y Leidenberger (2006, p. 269); Altshuler (1998).

${ }^{24}$ Según mis cálculos, basados en los datos contenidos en Comisión Nacional (1917, T. X), en 1914 las líneas de tranvías eléctricos representaban el 99,3 por cien del total existente en Argentina, atendiendo tanto a los pasajeros transportados como a los kilómetros recorridos.
} 
proceso de electrificación del subcontinente, al término de la Guerra no había conseguido arrumbar los tranvías tirados por mulas ${ }^{25}$. Por entonces, en las ciudades chilenas con sistemas tranviarios, incluyendo Santiago, todavía subsistía un considerable número de compañías y líneas a sangre ${ }^{26}$. Lo mismo ocurría en Ecuador ${ }^{27}$. En los países pequeños más atrasados, como Guatemala, sólo contaban con tranvía en la capital y todavía no habían emprendido su electrificación, o bien acababan de llevarla a cabo, como en Paraguay; o ni siquiera disponían de tranvía, como en Honduras ${ }^{28}$.

\subsection{La aplicación de la electricidad como fuerza motriz industrial}

En Estados Unidos, entre 1880 y 1930 la generación de la fuerza mecánica pasó de hacerse con motores hidráulicos primarios y máquinas de vapor a motores eléctricos, logrando con ello un ahorro de energía y grandes aumentos en la productividad, como ha demostrado Devine (1983). El despegue no se produjo verdaderamente antes del cambio de siglo. Todavía en 1899 los motores eléctricos aportaban únicamente el 5 por cien de la fuerza mecánica industrial de EEUU. Una década más tarde el porcentaje había saltado al 25 por ciento, y en la siguiente - 1909-1919 - adquirieron ya un peso mayoritario, reforzando su hegemonía a lo largo de los años $1920^{29}$. En otros países industrializados se observa igualmente el arranque en el primer decenio del siglo y una fuerte aceleración en el segundo, de manera que, una vez terminada la Guerra Mundial, la electricidad adquiere una presencia dominante como fuerza motriz para la industria (además de fuente de luz y calor) ${ }^{30}$.

Es harto difícil saber si la transición energética en América Latina progresó al mismo ritmo que en las economías más avanzadas. Para poder determinar la importancia absoluta y relativa de la electricidad como fuerza motriz industrial se precisan censos industriales. Desgraciadamente, la mayoría de países latinoamericanos no llevaron a cabo hasta más tarde sus primeros censos al resultar operaciones demasiado complejas y costosas para administraciones públicas con pocos recursos. Las naciones que sí

25 Smith (1919, p. 86).

26 Smith (1918, p. 57).

27 Halsey (1918, p. 290).

28 Halsey (1918, pp. 409 y 425); The Electrician, 3-1-1913, p. 653; 28-11-1913, p. 346; y 6-3-1914, p. 920

29 DuBoff (1979, pp. 31-2). La electricidad no revolucionó el sistema de organización industrial en Estados Unidos hasta la primera década del siglo XX, según Devine (1983); para David y Wright (1999) fue más bien a partir de la segunda década.

30 En Gran Bretaña, en 1907 la electricidad tan sólo representaba alrededor del 10 por cien de la fuerza industrial, mientras que en 1924 había aumentado a la mitad. En Alemania, hacia la primera fecha, los motores eléctricos ya aportaban del orden del 22 por cien de la fuerza mecánica. V. Byatt (1979, pp. 73-83). En 1929-30, los porcentajes se situaban en todos los países avanzados de Europa occidental por encima del 70 por ciento, excepto en Gran Bretaña (66\%) y Francia (49\%), según Segreto (1993, p. 350). 
levantaron algún censo industrial de cobertura nacional antes de la Segunda Guerra Mundial fueron las siguientes: Argentina en 1895, 1914 y 1935; Brasil en 1907 y 1920; Chile en 1894, 1911, 1928 y 1937; México en 1930 y 1935; República Dominicana en 1937; Uruguay en 1908 y 1930; y Venezuela en 1936. Algunos de esos censos proporcionan información que no es útil para nuestros propósitos, puesto que sólo registran el valor de la energía eléctrica consumida por los establecimientos industriales. En el resto, con pocas excepciones, no se distingue entre motores primarios, generadores eléctricos y motores eléctricos, lo que impide determinar con exactitud el peso relativo de estos últimos dentro de la fuerza mecánica empleada por la industria $^{31}$. Por todo ello, sólo podemos ilustrar de manera puntual y aproximada, para unos pocos países en algunos años concretos, el avance del aprovechamiento de la electricidad por parte de la industria latinoamericana (v. cuadro 1).

La electrificación de la industria argentina, tanto en 1914 como en 1935, no iba muy rezagada respecto a la de Estados Unidos. Lo mismo cabe decir de Brasil en 1920, merced al espectacular avance registrado en los tres lustros precedentes. Hacia 1907 la industria de Uruguay ya estaba dotada con más motores eléctricos —incluso en términos absolutos- que la de Brasil y Chile, pese a la enorme diferencia de tamaño entre estas economías. Por entonces, el sector secundario uruguayo había alcanzado un grado de electrificación no muy distante al de la industria estadounidense. En otras palabras, los datos comentados componen una imagen de la cual fácilmente se extraen conclusiones optimistas. En los países de Sudamérica más significados por su tamaño o por su nivel de desarrollo económico, el aprovechamiento de la electricidad por parte de la industria (y la minería) arrancó apenas con una década de retraso con respecto a la economía líder. Y su difusión en la segunda y tercera décadas del siglo parece haber seguido un ritmo no mucho menos intenso que en Estados Unidos y probablemente similar al de las naciones europeas más industrializadas, de forma que hacia 1930 la electricidad había reemplazado a las otras fuentes de energía mecánica en la mayoría de actividades industriales (y mineras). Es obvio que la universalización de la electricidad en el sector secundario del Cono Sur no puede desligarse de la pobre dotación de recursos

31 Los motores primarios son aquellos aparatos que transforman la energía contenida en diversas fuentes (agua, viento, vapor, etc.) en energía mecánica. Los generadores eléctricos son convertidores energéticos que, accionados por motores primarios, transforman la energía mecánica en energía eléctrica. Los motores eléctricos son máquinas que transforman la energía eléctrica en energía mecánica. Lo que debemos comparar es la potencia nominal de estos últimos en relación a la de los motores primarios, con exclusión de aquellos que se emplean para mover generadores eléctricos o están en reserva. Pero en los censos anteriores a 1939 muy raramente se proporciona información detallada sobre los motores primarios, lo que lleva a infravalorar la importancia relativa de los motores eléctricos. En I.B.G.E. (1954) se encuentra un examen detallado de las posibilidades y limitaciones de los censos industriales realizados por los países latinoamericanos. 


\section{CUADRO 1}

FUERZA MECÁNICA INDUSTRIAL DE ORIGEN ELÉCTRICO EN DIVERSOS PAÍSES ${ }^{1}$

\begin{tabular}{|c|c|c|c|c|}
\hline & c. 1907 & c. 1914 & 1920 & 1935 \\
\hline Argentina & & $\begin{array}{c}84.790 \mathrm{HP} \\
>30 \%\end{array}$ & & $\begin{array}{c}713.932 \mathrm{HP} \\
\leq 70 \%\end{array}$ \\
\hline Brasil & $\begin{array}{c}4.687 \mathrm{HP} \\
\geq 5 \%\end{array}$ & & $\begin{array}{c}167.118 \mathrm{HP} \\
\geq 54 \%\end{array}$ & \\
\hline Chile & $\begin{array}{c}2.392 \mathrm{HP} \\
>9 \%\end{array}$ & & $\begin{array}{c}26.653 \mathrm{HP} \\
>33 \%\end{array}$ & \\
\hline Uruguay & $\begin{array}{c}5.817 \mathrm{HP} \\
>17 \%\end{array}$ & & & \\
\hline EEUU $^{2}$ & $\begin{array}{c}4.582 .000 \mathrm{HP} \\
25 \%\end{array}$ & & $\begin{array}{c}15.612 .000 \mathrm{HP} \\
53 \%\end{array}$ & $\begin{array}{c}33.844 .000 \mathrm{HP} \\
78 \%\end{array}$ \\
\hline
\end{tabular}

Fuentes:

Argentina: Comisión Nacional (1917, t. VII, pp. 105-6) y Dirección General de Estadística de la Nación (1939, p. 74).

Brasil: Centro Industrial do Brasil (1909, p. 148) y Directoria Geral do Brasil (1927, pp. 72-87).

Chile: Sinopsis estadística (1906) y Oficina Central de Estadística (1921, p. 31).

Uruguay: Dirección General de Estadística (1911, p. 1.209).

Estados Unidos: DuBoff (1979).

Notas:

${ }^{(1)}$ Los porcentajes se refieren a la potencia de los motores eléctricos respecto a la del conjunto de los motores primarios.

(2) 1909,1919 y 1929.

El factor de conversión entre HP y kW es $1 \mathrm{~kW}=0,7457$ HP. United Nations (1987, p. 42).

energéticos alternativos, en contraste con Estados Unidos y otros países desarrollados. Y es igualmente cierto que el uso industrial de la electricidad en ambos lados del hemisferio occidental no resiste ninguna comparación si, en lugar de atender a la importancia de los motores eléctricos dentro del total de motores consideramos su potencia, tanto en valores absolutos como por habitante $^{32}$. Más importante aún, la valoración es optimista porque se basa en una evidencia empírica muy parcial, que no abarca las economías, mayoritarias en número, que tenían un sector industrial mucho menos desarrollado y dinámico.

32 Como botón de muestra, en 1919-20 Estados Unidos tenía 14,8 HP de motores eléctricos por cada 100 habitantes, mientras que Brasil sólo alcanzaba 0,6 HP, según mis cálculos. No podía ser de otro modo, siendo Estados Unidos la primera potencia industrial del mundo y los países latinoamericanos economías no industrializadas. 


\section{UNA APROXIMACIÓN CUANTITATIVA AL PROCESO DE ELECTRIFICACIÓN LATINOAMERICANO}

Las noticias y datos dispersos expuestos en las páginas precedentes sirven para formarse una mínima idea sobre la cronología y la intensidad de la adopción de la electricidad a lo largo y ancho de la región. Evidentemente, para adquirir un conocimiento más profundo y preciso de la cuestión deberíamos contar con información sistemática sobre la producción y el consumo de electricidad -idealmente, por tipos de uso-, o, en su defecto, sobre la capacidad instalada de las centrales eléctricas. Pero esa información, simplemente no existe para casi ninguno de esos países respecto al período anterior a los años 1930, e incluso en un buen número de ellos, para antes de 1950. En ausencia de estos datos básicos, no queda más remedio que acudir a las importaciones del equipo eléctrico. En concreto, propongo que recurramos a las exportaciones a los países latinoamericanos de esa clase de material por parte de Alemania, Gran Bretaña y Estados Unidos, G-3 para abreviar. En las siguientes líneas intentaré justificar mínimamente lo siguiente: primero, que las importaciones son un buen sucedáneo ( roxy) del gasto realizado en equipo eléctrico; segundo, que las exportaciones de G-3 son una aproximación razonable a las importaciones totales para ese tipo de bienes; y, tercero, que el gasto acumulado en equipo eléctrico guarda una clara relación con el nivel de electrificación alcanzado por los diversos países.

Respecto al primer punto, cabe decir que todos los indicios que tenemos apuntan a que la industria electrotécnica latinoamericana aún no se había gestado, o, en el mejor de los casos, se encontraba en su infancia. Así lo atestigua la experiencia de las economías más grandes y desarrolladas de la región. En Argentina, durante la Gran Guerra brotaron algunas líneas de producción de material eléctrico simple, como cables, y se creó una empresa capaz de suministrar componentes para el equipo de plantas de generación eléctrica ${ }^{33}$. Brasil, también en el curso del conflicto bélico, comenzó a fabricar algunos componentes de material y equipo eléctrico, tales como cable, aislantes y motores de baja potencia. No obstante, hasta finales de los años 1920 se producían en tan pequeña escala que los especialistas de la época juzgaban que esa industria estaba todavía en sus inicios ${ }^{34}$. En definitiva, al término de la primera república la economía brasileña continuaba dependiendo casi exclusivamente de la importación del material eléctrico que necesitaba ${ }^{35}$. En México, los establecimientos de fabricación e instalación de material eléctrico registrados en el primer censo industrial, levantado en

33 V. The Electrician, 1-12-1916, p. 300; Smith (1919, pp. 16-7).

${ }^{34}$ L'Électricien. Revue Internationale de l'électricité et de ses applications, 1-7-1926, p. e-320-1; U.S. Tariff Comission (1945, p. 60). V. también el diagnóstico coincidente de Wilkins (1974, pp. 28 y 72).

35 CIER (1989, p. 157). 
1929, configuraban un sector extremadamente pequeño ${ }^{36}$. Chile, uno de los países que antes de la Gran Depresión hizo más progresos en la senda industrializadora, carecía de industria electrotécnica ${ }^{37}$. En Cuba tampoco existía ${ }^{38}$. Por supuesto, Centroamérica se encontraba en la misma situación ${ }^{39}$.

Vayamos con el segundo argumento. Es sabido que la industria electrotécnica de Alemania, Gran Bretaña y Estados Unidos dominó las exportaciones mundiales durante la época de la revolución eléctrica. La participación de los tres países se mantuvo por encima del 80 por ciento ${ }^{40}$. En Latinoamérica resultó más aplastante que en otros mercados la hegemonía de los cuatro grupos industriales de las mencionadas potencias industriales: General Electric de Estados Unidos, y también Gran Bretaña a través de la filial de Thomson-Houston perteneciente a la primera; Westinghouse de Estados Unidos e igualmente Gran Bretaña por la filial allí establecida; AEG, de Alemania; y Siemens de Alemania y Gran Bretaña mediante su filial. Los dos gigantes de la industria electrotécnica alemana (A.E.G. y Siemens) crearon una red de sociedades filiales de comercialización de sus productos, establecida en casi todos los mercados latinoamericanos ${ }^{41}$. Ciertamente, algunas empresas de otras naciones europeas - Suiza, Francia, Italia, Suecia - tecnológicamente muy avanzadas fueron capaces de ofrecer equipos de alta calidad y fiabilidad al especializarse en determinados tipos de bienes, gracias a lo cual se adueñaron de pequeños segmentos de los mercados latinoamericanos $^{42}$. Pero las dudas que puedan albergarse al respecto se desvanecen cuando se lleva a cabo una contrastación empírica amplia. El cuadro 2 confirma, en efecto, que las exportaciones de G-3 tuvieron tanto peso dentro de las compras al exterior de material eléctrico realizadas por Latinoamérica que podemos estar razonablemente seguros que aquéllas dan una fiel imagen de éstas, al igual que ocurre con el equipo de transporte y la maquinaria ${ }^{43}$.

El cuadro no resuelve, empero, la cuestión de la representatividad de G-3 a lo largo del tiempo. ¿Se mantuvo invariable, o bien sufrió cambios significativos entre el período anterior y posterior a la Guerra Mundial, y durante la misma? Tomemos Brasil como botón de muestra, cuyas compras de material

36 Los datos se encuentran en Dirección General de Estadística, 1935.

37 L'Électricien. Revue Internationale de l'électricité et de ses applications, 15-4-1925, p. e-194; U.S. Department of Commerce (1927b, pp. 22-3).

38 Smith (1917); U.S. Department of Commerce, Commerce Reports, 4-4-1932, p. 45.

39 Para Guatemala, v. L'Électricien. Revue Internationale de l'électricité et de ses applications, 1-51925, p e-221; para Costa Rica, L'Électricien. Revue Internationale de l'électricité et de ses applications, 15-5-1928, p. e-255.

40 V. Hertner (1987, p. 125), (1989, p. 153).

41 Rippy (1948); Young (1995, pp. 114-7).

42 Broder (1987, pp. 184-5); Hertner (1987, p. 125); y U.S. Department of Commerce, Commerce Reports 25-5-1925, pp. 462-3.

43 El ejercicio de verificación se ha realizado para el año 1925 porque puede tomarse como representativo de la situación existente en la década de 1920, y también porque alrededor de esa fecha, pero no mucho antes, las estadísticas oficiales del comercio exterior de los países latinoamericanos dan información sobre el material eléctrico importado. Para el equipo de transporte y la maquinaria, Tafunell (2009a) y (2009b). 


\section{CUADRO 2}

IMPORTACIONES DE EQUIPO ELÉCTRICO PROCEDENTES DE G-3, COMO PORCENTAJE DEL TOTAL. AÑO 1925*

\begin{tabular}{|l|c|}
\hline Argentina & 83,1 \\
\hline Bolivia & $85,1(89,3)^{\mathrm{a}}$ \\
\hline Brasil & $80,8(86,8)$ \\
\hline Chile & 91,0 \\
\hline Colombia & 97,9 \\
\hline Costa Rica & 95,2 \\
\hline Cuba & 81,6 \\
\hline Ecuador & 78,6 \\
\hline El Salvador & 96,3 \\
\hline Guatemala & 92,6 \\
\hline Haití & 95,8 \\
\hline México & 94,8 \\
\hline Nicaragua & 92,4 \\
\hline Paraguay & $83,6^{\mathrm{b}}$ \\
\hline Perú & $90,0^{\mathrm{c}}$ \\
\hline República Dominicana & $91,8^{\mathrm{d}}$ \\
\hline América Latina (16) & 85,9 \\
\hline
\end{tabular}

Fuentes:

Elaboración propia a partir de las estadísticas oficiales del comercio exterior. El porcentaje de América Latina ha sido obtenido convirtiendo los valores en monedas nacionales a dólares según el tipo de cambio consignado en U.S. Department of Commerce (1926).

Notas:

*Los valores entre paréntesis se refiere al equipo de generación y transmisión. En los demás casos es el total de material eléctrico.

a Calculado restando a la importaciones totales las procedentes de Argentina, Chile y Perú porque puede presumirse que eran originarias de EEUU o Europa.

${ }^{\mathrm{b}}$ Calculado restando a las importaciones totales las procedentes de Argentina al presumirse que eran originarias de EEUU o Europa.

${ }^{\mathrm{c}}$ Calculado sobre las cantidades (peso), puesto que los valores contienen errores al ser inconsistentes los valores unitarios de algunos renglones.

${ }^{\mathrm{d}}$ Las importaciones procedentes de Puerto Rico han sido consideradas de EEUU.

eléctrico venían a suponer $\frac{1}{4}$ del total adquirido por Latinoamérica ${ }^{44}$. Según mis cálculos (v. cuadro 3), no se aprecia una tendencia clara en la cuota de mercado

${ }^{44}$ La elección de este país ha venido dada también por la circunstancia que es una de las pocas naciones de la región cuyas estadísticas comerciales especifican el material eléctrico importado en 


\section{CUADRO 3}

EQUIPO ELÉCTRICO PROCEDENTE DE G-3 IMPORTADO POR BRASIL, COMO PORCENTAJE DEL TOTAL DE IMPORTACIONES DE EQUIPO ELÉCTRICO

\begin{tabular}{|c|c|c|}
\hline Año & Total material eléctrico & Equipo de generación y transmisión \\
\hline 1910 & 91,4 & - \\
\hline 1911 & 91,6 & - \\
\hline 1912 & 84,4 & - \\
\hline 1913 & 90,1 & 93,4 \\
\hline 1914 & 85,9 & 93,7 \\
\hline 1915 & 87,9 & 87,8 \\
\hline 1916 & 87,9 & 84,2 \\
\hline 1917 & 88,7 & 64,7 \\
\hline 1918 & 88,4 & 81,2 \\
\hline 1919 & 90,9 & 92,4 \\
\hline 1920 & 87,1 & 94,2 \\
\hline 1921 & 85,1 & 95,9 \\
\hline 1922 & 75,9 & 86,3 \\
\hline 1923 & 76,8 & 89,5 \\
\hline 1924 & - & - \\
\hline 1925 & 80,8 & 86,8 \\
\hline 1926 & 80,2 & 82,0 \\
\hline 1927 & 77,5 & 82,5 \\
\hline 1928 & 70,8 & 87,6 \\
\hline 1929 & 76,4 & 89,9 \\
\hline 1930 & 72,4 & 87,2 \\
\hline
\end{tabular}

Fuente:

Officinas da estatística comercial (1914-1932).

de G-3 de equipo de generación y transmisión, aunque sí se advierte una tendencia ligeramente declinante en la cuota correspondiente al conjunto del material eléctrico. En todo caso, la variabilidad de las cuotas es reducida, lo que, unido a su muy elevado valor, asegura unos márgenes de error moderados a una estimación basada en las exportaciones de G-3 como la que aquí se presenta.

\section{(F'note continued)}

los años previos a la Guerra Mundial, según partidas arancelarias estables y perfectamente comparables, entre las que pueden aislarse el equipo de generación, transmisión y distribución. 
Antes de examinar las series de equipo eléctrico importado todavía tenemos que resolver una incógnita: ¿hasta qué punto el valor de ese material refleja de manera fidedigna el nivel de desarrollo eléctrico logrado? $\mathrm{He}$ indicado que desconocemos las magnitudes de la producción y el consumo de electricidad. Tampoco sabemos cómo evolucionó la capacidad instalada de las plantas; ¡ni siquiera sabemos cuál era su número! Con todo, estamos en condiciones de estimar de manera razonablemente aproximada a cuánto ascendía dicha capacidad a nivel nacional en el año 1930 (v. cuadro 4). Pues bien, al cruzar los datos de ambas variables —el acumulado de las importaciones de bienes eléctricos entre 1891 y 1930, y la capacidad instalada en esta última fecha- se descubre que están estrechamente asociadas (gráfico 1). El gráfico 1 respalda la bondad de las exportaciones de material eléctrico de G-3 como indicador del grado de electrificación alcanzado por los países latinoamericanos. La correlación entre ambas variables, en una función exponencial, es suficientemente buena para detectar que ciertos pares de valores que se apartan del nivel pronosticado son seguramente fruto de errores de estimación. En el caso de Bolivia y Paraguay, no cabe duda alguna que mis agregados de bienes eléctricos infravaloran notablemente los volúmenes importados. El desvío de Venezuela, y acaso el de Ecuador, serían imputables, en cambio, a una subestimación de la capacidad instalada. No tengo explicación para la desviación de Costa Rica, la única que, junto con las anteriores, resulta significativa.

Aquí se propone, pues, una aproximación a las importaciones totales de material y equipo eléctrico realizadas por los países latinoamericanos basada en las exportaciones de sus tres principales proveedores. Es el mismo método que he seguido en trabajos anteriores para estimar las inversiones en bienes de equipo. La elaboración no está exenta de limitaciones y dificultades, como he descrito detalladamente en esos trabajos ${ }^{45}$. Una de las limitaciones estriba en que las fuentes no permiten que nos remontemos más atrás del año 1891; incluso es dudoso que durante los primeros años posteriores a esta fecha registren la totalidad del equipo eléctrico exportado ${ }^{46}$. En todo caso, estos déficit iniciales desaparecen al cabo de unos años. En parte, tales problemas se resuelven reescalando las series de exportaciones con arreglo a la regresión entre su valor acumulado y la capacidad instalada ${ }^{47}$. El cuadro 5 contiene los

45 En Tafunell (2009b) se exponen los problemas metodológicos que plantean las estadísticas de G-3 para cuantificar las exportaciones de maquinaria y otros bienes de equipo, así como las opciones tomadas para resolverlos.

46 La estadística estadounidense no informa sobre el material eléctrico hasta 1891, sin especificar su carácter ni hacer ninguna distinción hasta 1909. A principios de la década de 1890 las estadísticas alemana y británica no registran por separado más que el material de telegrafía y telefonía.

47 No he reescalado las series de Costa Rica, Ecuador y Venezuela, así como las de Haití y República Dominicana. Las primeras no se han ajustado ante la sospecha que los datos disponibles sobre capacidad instalada son erróneos. En el caso de las dos últimas no han sido ajustadas por la sencilla razón que se desconoce la capacidad instalada. 
CUADRO 4

CAPACIDAD ELÉCTRICA INSTALADA EN 1930, EN KW*

\begin{tabular}{|c|c|}
\hline Argentina $^{1}$ & 820.241 \\
\hline Bolivia $^{2}$ & 25.200 \\
\hline Brasil $^{3}$ & 694.872 \\
\hline Colombia $^{4}$ & 59.564 \\
\hline Costa Rica ${ }^{5}$ & 23.424 \\
\hline Cuba $^{6}$ & 357.147 \\
\hline Chile $^{7}$ & 302.000 \\
\hline Ecuador $^{8}$ & 5.491 \\
\hline El Salvador ${ }^{9}$ & 7.174 \\
\hline Guatemala & 18.500 \\
\hline Haití & n.d. \\
\hline Honduras & 4.791 \\
\hline México $^{10}$ & 500.000 \\
\hline Nicaragua & 3.261 \\
\hline Panamá (incluida Zona del Canal) & 6.931 \\
\hline Paraguay $^{11}$ & 2.850 \\
\hline Perú $^{12}$ & 61.097 \\
\hline R. Dominicana & n.d. \\
\hline Uruguay & 50.721 \\
\hline Venezuela $^{13}$ & 20.888 \\
\hline América Latina & 2.964 .151 \\
\hline
\end{tabular}

Fuentes y notas:

"A menos que se indique lo contrario, los datos proceden de Bradley (1931).

(1) He dado por válida la cifra que ofrece Bradley para 1926. La cifra correspondiente a 1930 ha sido estimada proyectando la tasa de crecimiento del período 1916-27, la cual es sólo ligeramente superior a la de 1927-35.

(2) CIER (1989: 148).

(3) Ministerio da Agricultura (1935: 343).

(4) He seguido el mismo procedimiento que para Argentina.

(5) He considerado que la cifra que ofrece Bradley como capacidad hidroeléctrica (31.400 HP) corresponde en realidad a la capacidad total, pues según otras fuentes la primera ascendía a $18.000 \mathrm{~kW}$

(6) He estimado la potencia de las centrales públicas en $179 \mathrm{MW}$, partiendo de que, según el Anuario Estadístico de Cuba (1952: 127), la capacidad de las plantas censadas (170 MW) cubría más del 90\% del total

(footnote continued) 
(he supuesto 95\%). Los 162 MW corresponden a la capacidad de los centrales azucareros de 1927, según Altshuler (1998). He supuesto que no aumentaron su capacidad hasta 1930. He añadido arbitrariamente un $10 \%$ para el resto de autoproductores.

(7) CIER (1989: 223).

(8) Según Bradley, la capacidad hidroeléctrica era $6.400 \mathrm{HP}$ a fin de 1930. He añadido un 15\% más, siguiendo su juicio de que sólo una pequeña proporción de la energía eléctrica era de origen térmico (p. 104).

(9) El dato resulta de aceptar para el año 1927 los datos de U.S. Department of Commerce (1927a), y extrapolar la tasa de crecimiento del período 1916-27, según Bradley (1931: 72).

(10) Comisión Nacional de Irrigación (1931: 23-4).

(11) Bradley consigna $2.700 \mathrm{~kW}$ de potencia térmica (a madera), a los cuales he sumado la pequeña central hidroeléctrica que, según este autor existía, y cuya capacidad he supuesto que era de $200 \mathrm{HP}$.

${ }^{(12)}$ He extrapolado a 1930 la tasa de crecimiento de la capacidad instalada entre 1934 y 1940 . Estos dos datos proceden de CEPAL (1956). El resultado es coherente con la cifra de potencia hidroeléctrica instalada en 1930, según Bradley (55.000 HP), si suponemos que en aquella fecha había la misma proporción entre hidro y termo que en 1940, según el Anuario Estadístico de Perú de 1945.

${ }^{(13)}$ Se refiere al año 1929.

\section{GRÁFICO 1 \\ IMPORTACIONES DE EQUIPO ELÉCTRICO Y CAPACIDAD DE GENERACIÓN ELÉCTRICA}

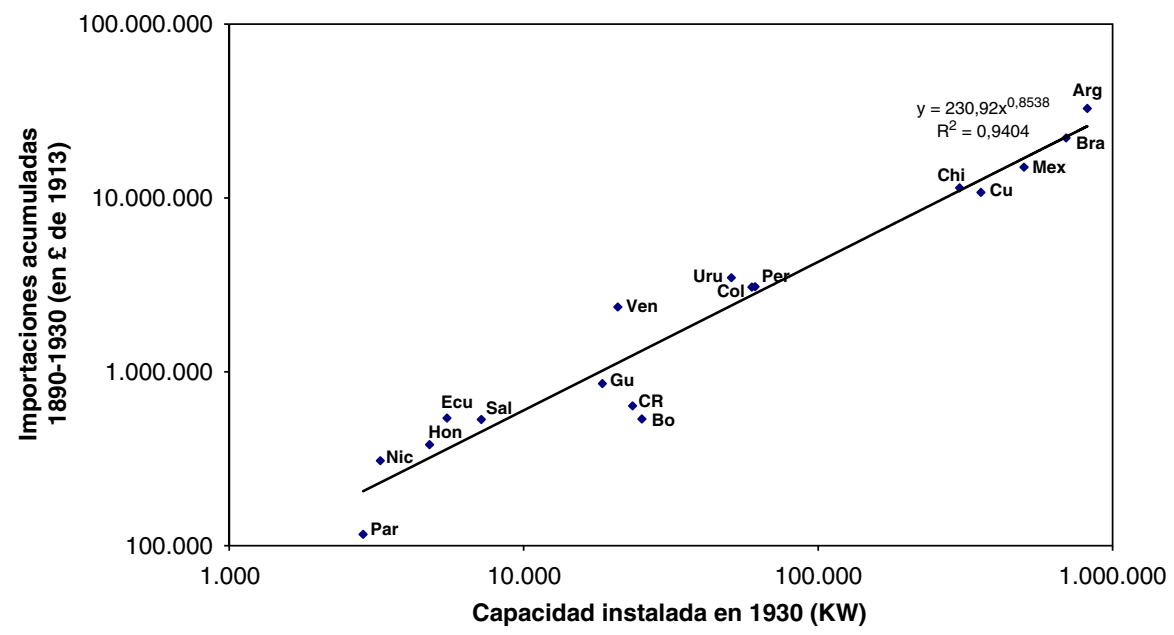

Fuentes: Cuadro 4 y elaboración basada en las fuentes consignadas en el cuadro 5

resultados de dicho cálculo, los cuales, según todos los indicios, dan una imagen razonablemente próxima a la realidad.

El cuadro 6 traduce las series del cuadro precedente a tasas de crecimiento en los diversos subperíodos históricos, lo que exhibe la existencia de diferentes ritmos del proceso de electrificación tanto a lo largo del tiempo como entre países. Vayamos con lo primero. El gasto en equipo eléctrico se 
CUADRO 5

VALOR ESTIMADO, EN LIBRAS DE 1913, DE LAS IMPORTACIONES DE MATERIAL ELÉCTRICO DE G-3 SEGÚN EL AJUSTE ENTRE IMPORTACIONES ACUMULADAS Y CAPACIDAD DE GENERACIÓN INSTALADA*

\begin{tabular}{|c|c|c|c|c|c|c|c|c|c|c|c|c|c|c|c|c|c|c|c|c|}
\hline : & 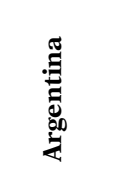 & $\frac{\pi}{:}$ & ") & $\begin{array}{l}\frac{\pi}{3} \\
\frac{0}{0} \\
\frac{0}{0}\end{array}$ & 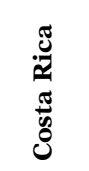 & $\frac{\pi}{3}$ & 尝 & 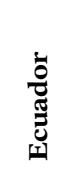 & 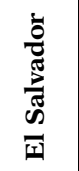 & 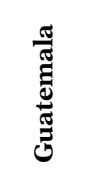 & 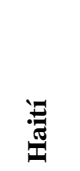 & 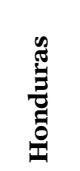 & 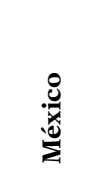 & 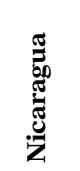 & 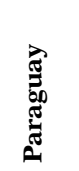 & 䞶 & 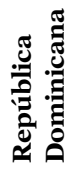 & $\begin{array}{l}\overrightarrow{3} \\
\vec{J} \\
\vec{J} \\
\vec{b}\end{array}$ & 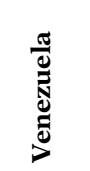 & 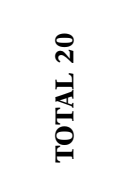 \\
\hline 1891 & 11.634 & 6 & 297.028 & 10.616 & 5.533 & 38.535 & 19.880 & 2.091 & 6.552 & 14.299 & 2.717 & 1.173 & 67.979 & 1.692 & 1.218 & 14.074 & 345 & 7.178 & 11.069 & 513.619 \\
\hline 1892 & 35.012 & 0 & 146.542 & 9.101 & 5.341 & 47.762 & 25.821 & 1.562 & 5.372 & 9.714 & 2.002 & 561 & 46.013 & 3.525 & 0 & 6.442 & 593 & 2.549 & 11.289 & 359.200 \\
\hline 1893 & 16.268 & 0 & 45.091 & 8.267 & 4.378 & 42.807 & 44.492 & 1.527 & 2.960 & 7.552 & 1.449 & 337 & 34.921 & 618 & 0 & 4.313 & 1.184 & 2.597 & 11.330 & 230.091 \\
\hline 1894 & 22.225 & 0 & 64.294 & 6.728 & 5.531 & 39.659 & 20.158 & 1.286 & 2.809 & 8.722 & 1.277 & 867 & 52.958 & 1.267 & 14 & 3.114 & 3.210 & 3.107 & 13.035 & 250.263 \\
\hline 1895 & 34.977 & 0 & 347.777 & 6.987 & 8.689 & 29.555 & 18.409 & 1.545 & 3.717 & 15.119 & 1.429 & 1.366 & 76.671 & 2.937 & 178 & 6.636 & 3.766 & 3.885 & 16.861 & 580.503 \\
\hline 1896 & 48.143 & 0 & 114.477 & 12.070 & 8.673 & 16.628 & 19.203 & 2.267 & 4.996 & 17.963 & 2.011 & 1.056 & 85.964 & 1.707 & 57 & 10.227 & 2.702 & 5.145 & 17.473 & 370.763 \\
\hline 1897 & 63.310 & 0 & 124.867 & 12.974 & 6.928 & 9.905 & 15.038 & 2.225 & 4.634 & 17.054 & 872 & 1.571 & 135.784 & 2.050 & 40 & 8.620 & 1.971 & 3.881 & 18.564 & 430.290 \\
\hline 1898 & 230.075 & 80 & 67.520 & 10.419 & 13.775 & 18.304 & 20.602 & 3.065 & 2.805 & 7.629 & 452 & 1.339 & 111.934 & 1.783 & 288 & 4.602 & 1.431 & 7.722 & 10.457 & 514.282 \\
\hline 1899 & 157.243 & 323 & 96.450 & 7.853 & 16.940 & 45.428 & 73.595 & 5.634 & 2.375 & 5.223 & 524 & 878 & 126.175 & 1.628 & 1.522 & 12.206 & 2.582 & 8.785 & 5.208 & 570.571 \\
\hline 1900 & 119.368 & 759 & 483.103 & 6.032 & 16.720 & 61.924 & 30.901 & 7.143 & 3.375 & 5.652 & 1.641 & 952 & 131.160 & 2.013 & 195 & 35.654 & 4.022 & 7.265 & 4.778 & 922.658 \\
\hline 1901 & 103.595 & 5.761 & 82.679 & 5.325 & 10.584 & 51.498 & 18.961 & 3.876 & 2.542 & 5.144 & 1.452 & 900 & 94.523 & 1.144 & 1.466 & 12.951 & 2.776 & 6.705 & 6.131 & 418.014 \\
\hline 1902 & 73.631 & 522 & 130.363 & 5.432 & 10.107 & 39.513 & 18.044 & 3.222 & 1.701 & 3.987 & 764 & 463 & 176.156 & 2.146 & 142 & 18.769 & 1.144 & 5.450 & 5.980 & 497.536 \\
\hline 1903 & 94.193 & 1.534 & 111.233 & 6.816 & 23.509 & 39.407 & 35.462 & 4.807 & 2.143 & 3.231 & 1.298 & 782 & 165.410 & 2.282 & 284 & 34.217 & 939 & 2.946 & 10.240 & 540.732 \\
\hline 1904 & 111.982 & 1.726 & 168.510 & 6.317 & 22.393 & 111.928 & 42.193 & 5.109 & 2.546 & 4.479 & 837 & 1.495 & 166.088 & 1.208 & 1.350 & 29.872 & 1.539 & 4.787 & 18.743 & 707.097 \\
\hline 1905 & 221.092 & 3.134 & 208.255 & 11.894 & 11.118 & 149.226 & 232.740 & 5.660 & 4.165 & 6.385 & 1.103 & 1.766 & 275.728 & 1.931 & 449 & 39.539 & 2.796 & 11.779 & 21.617 & 1.220 .664 \\
\hline 1906 & 548.650 & 13.402 & 373.611 & 7.192 & 19.714 & 158.060 & 166.856 & 6.602 & 4.427 & 6.793 & 609 & 1.964 & 348.897 & 2.119 & 4.215 & 63.514 & 3.007 & 60.733 & 30.204 & 1.840 .742 \\
\hline 1907 & 629.358 & 23.823 & 458.859 & 13.952 & 24.645 & 186.339 & 197.610 & 8.366 & 5.512 & 11.764 & 590 & 1.377 & 377.109 & 1.610 & 1.385 & 86.431 & 2.577 & 179.800 & 37.643 & 2.278 .025 \\
\hline 1908 & 556.965 & 8.203 & 426.216 & 9.959 & 20.793 & 155.416 & 357.122 & 6.612 & 4.238 & 6.859 & 408 & 915 & 283.428 & 990 & 783 & 35.428 & 2.331 & 78.414 & 20.929 & 2.016.775 \\
\hline 1909 & 654.819 & 22.773 & 647.172 & 18.147 & 35.706 & 168.675 & 158.786 & 7.446 & 6.346 & 9.523 & 1.909 & 2.083 & 511.774 & 1.870 & 75 & 43.719 & 3.755 & 56.982 & 20.544 & 2.444 .485 \\
\hline 1910 & 1.037 .371 & 23.542 & 1.157 .143 & 29.434 & 40.458 & 291.935 & 248.523 & 8.045 & 9.860 & 10.261 & 7.974 & 4.537 & 840.129 & 3.631 & 4.856 & 45.747 & 5.776 & 143.992 & 28.268 & 4.027 .186 \\
\hline
\end{tabular}




\begin{tabular}{|c|c|c|c|c|c|c|c|c|c|c|c|c|c|c|c|c|c|c|c|c|}
\hline 1911 & 850.505 & 24.118 & 1.103 .550 & 26.531 & 30.890 & 265.355 & 245.195 & 7.331 & 8.591 & 9.456 & 6.883 & 6.895 & 612.431 & 4.750 & 1.122 & 38.908 & 7.637 & 81.345 & 29.221 & 3.415 .120 \\
\hline 1912 & 999.586 & 39.652 & 1.241 .800 & 35.359 & 43.558 & 324.533 & 368.093 & 10.754 & 10.411 & 16.091 & 3.177 & 6.568 & 568.191 & 3.529 & 34.990 & 59.905 & 23.746 & 105.877 & 26.612 & 4.097.582 \\
\hline 1913 & 1.141 .594 & 58.818 & 1.169 .301 & 52.571 & 51.932 & 347.207 & 402.016 & 13.655 & 11.689 & 20.109 & 4.192 & 5.718 & 495.432 & 5.326 & 34.142 & 87.629 & 28.142 & 84.343 & 38.081 & 4.332 .799 \\
\hline 1914 & 709.511 & 31.792 & 572.655 & 55.424 & 48.706 & 307.655 & 216.188 & 21.532 & 9.172 & 12.837 & 2.555 & 9.562 & 264.645 & 5.209 & 1.173 & 56.536 & 14.015 & 46.702 & 34.395 & 2.639 .872 \\
\hline 1915 & 238.676 & 21.240 & 261.705 & 42.264 & 33.077 & 344.432 & 103.295 & 18.736 & 9.282 & 7.525 & 1.487 & 9.834 & 144.665 & 3.384 & 404 & 45.689 & 7.415 & 38.472 & 38.378 & 1.516 .668 \\
\hline 1916 & 226.926 & 14.867 & 368.864 & 44.679 & 23.814 & 487.984 & 217.506 & 14.978 & 11.126 & 10.426 & 4.066 & 8.548 & 185.224 & 3.766 & 812 & 52.581 & 10.525 & 27.471 & 43.358 & 1.880 .455 \\
\hline 1917 & 309.635 & 15.037 & 444.281 & 44.229 & 16.548 & 559.534 & 295.447 & 16.765 & 10.025 & 10.899 & 13.889 & 6.924 & 240.024 & 4.193 & 3.911 & 88.437 & 19.992 & 38.134 & 38.892 & 2.311 .638 \\
\hline 1918 & 253.607 & 29.494 & 326.633 & 28.189 & 7.258 & 415.853 & 325.335 & 10.179 & 5.437 & 6.548 & 13.002 & 3.423 & 233.222 & 3.562 & 5.313 & 70.468 & 19.239 & 31.383 & 24.337 & 1.917.897 \\
\hline 1919 & 323.653 & 62.097 & 585.188 & 47.169 & 12.772 & 424.280 & 233.193 & 15.106 & 10.528 & 15.416 & 5.432 & 5.838 & 302.637 & 5.716 & 1.758 & 130.174 & 15.604 & 70.888 & 29.114 & 2.341 .834 \\
\hline 1920 & 609.339 & 44.459 & 863.164 & 97.868 & 32.506 & 1.062 .166 & 247.256 & 24.759 & 17.779 & 22.893 & 10.209 & 11.566 & 553.264 & 14.082 & 6.535 & 264.824 & 39.036 & 72.206 & 54.998 & 4.143.228 \\
\hline 1921 & 789.937 & 95.107 & 763.061 & 182.298 & 34.713 & 832.100 & 398.691 & 12.010 & 13.903 & 33.181 & 6.703 & 17.222 & 872.863 & 8.388 & 2.323 & 172.200 & 44.086 & 60.166 & 66.747 & 4.495 .958 \\
\hline 1922 & 643.562 & 29.711 & 402.030 & 52.428 & 19.701 & 293.433 & 445.305 & 20.108 & 8.342 & 18.357 & 4.014 & 14.778 & 473.644 & 4.213 & 972 & 64.475 & 24.260 & 55.301 & 44.947 & 2.639.798 \\
\hline 1923 & 1.074 .678 & 71.327 & 598.325 & 83.492 & 40.278 & 512.684 & 712.582 & 25.285 & 15.780 & 44.636 & 10.160 & 28.662 & 530.078 & 8.673 & 1.196 & 125.299 & 23.202 & 88.083 & 54.628 & 4.091 .746 \\
\hline 1924 & 896.237 & 65.485 & 822.013 & 102.736 & 62.974 & 790.083 & 474.341 & 24.200 & 22.780 & 86.637 & 9.468 & 17.430 & 1.031 .277 & 15.475 & 3.933 & 142.783 & 27.231 & 62.620 & 80.111 & 4.800 .045 \\
\hline 1925 & 1.139 .018 & 57.354 & 923.061 & 120.210 & 54.198 & 853.718 & 436.011 & 27.588 & 31.586 & 54.975 & 10.396 & 16.433 & 815.906 & 13.905 & 4.953 & 140.462 & 27.539 & 96.681 & 111.581 & 5.048 .566 \\
\hline 1926 & 1.673 .237 & 71.365 & 1.020 .767 & 194.048 & 51.190 & 616.556 & 1.018 .788 & 42.279 & 35.668 & 102.999 & 18.993 & 20.955 & 875.652 & 12.688 & 4.278 & 125.955 & 25.247 & 100.573 & 199.879 & 6.299 .952 \\
\hline 1927 & 1.886 .333 & 66.791 & 1.163 .162 & 294.873 & 56.149 & 645.030 & 584.225 & 34.198 & 34.088 & 94.875 & 16.947 & 25.775 & 994.690 & 11.957 & 7.307 & 169.901 & 50.479 & 126.840 & 217.439 & 6.575 .184 \\
\hline 1928 & 2.404 .169 & 110.521 & 1.353 .984 & 392.150 & 119.870 & 575.051 & 649.500 & 36.895 & 34.388 & 109.752 & 15.977 & 24.375 & 1.009 .668 & 20.736 & 33.108 & 128.049 & 60.096 & 130.182 & 236.498 & 7.558.788 \\
\hline 1929 & 2.342 .447 & 143.880 & 1.704 .024 & 379.696 & 121.374 & 695.110 & 780.986 & 38.733 & 39.207 & 100.497 & 21.218 & 21.755 & 1.124 .000 & 21.788 & 16.343 & 187.070 & 39.494 & 165.628 & 266.558 & 8.334 .429 \\
\hline 1930 & 2.586 .748 & 163.741 & 1.214 .531 & 274.657 & 69.405 & 664.605 & 1.104 .438 & 39.026 & 29.533 & 60.254 & 20.019 & 31.844 & 1.516 .514 & 21.269 & 22.598 & 149.420 & 50.414 & 316.389 & 403.632 & 8.960 .563 \\
\hline
\end{tabular}

Fuentes y notas:

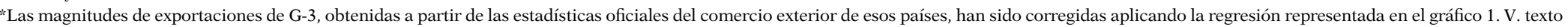

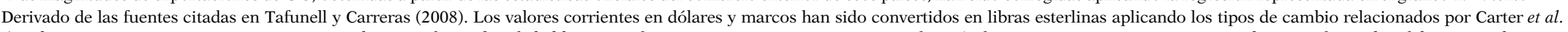

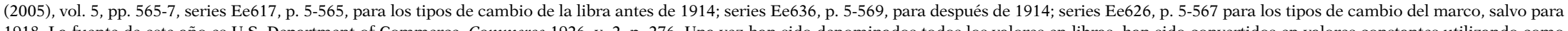

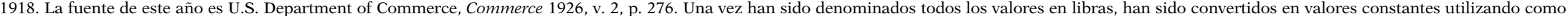

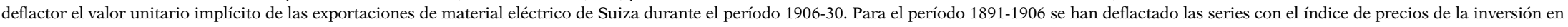
General plant and machinery del Reino Unido, v. Feinstein (1988), table XXIII, p. 470-1. 


\section{CUADRO 6}

TASAS DE CRECIMIENTO ANUAL DE LAS IMPORTACIONES DE MATERIAL ELÉCTRICO (\%)

\begin{tabular}{|c|c|c|c|c|c|c|c|c|c|c|c|c|c|c|c|c|c|c|c|c|}
\hline 突 & 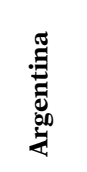 & 㞼 & 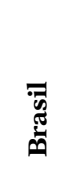 & $\begin{array}{l}\frac{\pi}{0} \\
\frac{0}{0} \\
\frac{0}{8}\end{array}$ & 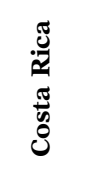 & हే & 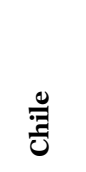 & 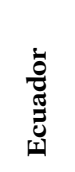 & 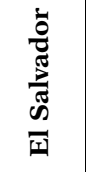 & $\begin{array}{l}\frac{\pi}{\pi} \\
\text { हूँ } \\
\text { हुँ }\end{array}$ & 䔍 & 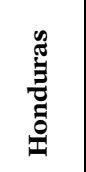 & 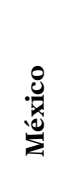 & 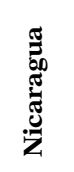 & 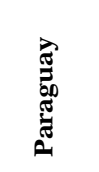 & 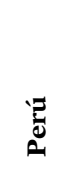 & 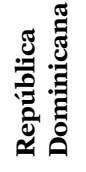 & 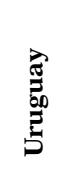 & $\begin{array}{l}\frac{\pi}{0} \\
\frac{0}{2} \\
\frac{0}{00} \\
>\end{array}$ & 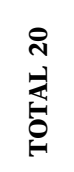 \\
\hline 1891-1929 & 15,0 & 30,4 & 4,7 & 9,9 & 8,5 & 7,9 & 10,1 & 8,0 & 4,8 & 5,3 & 5,6 & 8,0 & 7,7 & 7,0 & 7,1 & 7,0 & 13,3 & 8,6 & 8,7 & 7,6 \\
\hline 1891-1913 & 23,2 & 51,9 & 6,4 & 7,5 & 10,7 & 10,5 & 14,6 & 8,9 & 2,7 & 1,6 & 2,0 & 7,5 & 9,4 & 5,4 & 16,4 & 8,7 & 22,2 & 11,9 & 5,8 & 10,2 \\
\hline 1913-1929 & 4,6 & 5,8 & 2,4 & 13,2 & 5,4 & 4,4 & 4,2 & 6,7 & 7,9 & 10,6 & 10,7 & 8,7 & 5,3 & 9,2 & $-4,5$ & 4,9 & 2,1 & 4,3 & 12,9 & 4,2 \\
\hline 1891-1900 & 29,5 & 71,5 & 5,6 & $-6,1$ & 13,1 & 5,4 & 5,0 & 14,6 & $-7,1$ & $-9,8$ & $-5,4$ & $-2,3$ & 7,6 & 1,9 & $-18,4$ & 10,9 & 31,4 & 0,1 & $-8,9$ & 6,7 \\
\hline 1901-1913 & 22,1 & 21,4 & 24,7 & 21,0 & 14,2 & 17,2 & 29,0 & 11,1 & 13,6 & 12,0 & 9,2 & 16,7 & 14,8 & 13,7 & 30,0 & 17,3 & 21,3 & 23,5 & 16,4 & 21,5 \\
\hline 1913-1920 & $-8,6$ & $-3,9$ & $-4,2$ & 9,3 & $-6,5$ & 17,3 & $-6,7$ & 8,9 & 6,2 & 1,9 & 13,6 & 10,6 & 1,6 & 14,9 & $-21,0$ & 17,1 & 4,8 & $-2,2$ & 5,4 & $-0,6$ \\
\hline 1921-1929 & 14,6 & 5,3 & 10,6 & 9,6 & 16,9 & $-2,2$ & 8,8 & 15,8 & 13,8 & 14,9 & 15,5 & 3,0 & 3,2 & 12,7 & 27,6 & 1,0 & $-1,4$ & 13,5 & 18,9 & 8,0 \\
\hline
\end{tabular}

Fuentes: Cuadro 5 
expandió a una tasa de casi el 8 por cien anual durante las cuatro décadas que podemos identificar como la era de la revolución eléctrica. Es una tasa propia de una actividad emergente dotada de un enorme potencial de crecimiento y que está protagonizando un cambio económico de gran calado. Pero el ascenso no fue constante. Latinoamérica progresó más rápidamente antes de la Primera Guerra Mundial, sobre todo entre 1901 y 1913. En esta década larga prodigiosa las incorporaciones de equipo eléctrico crecieron a una tasa anual del 21,8 por ciento, es decir, se decuplicaron. A continuación, sufrieron una aguda contracción, como consecuencia de los problemas de abastecimiento ocasionados por el conflicto bélico. La recuperación, iniciada en 1920, no pudo darse por completada hasta 1924, cuando se superó el nivel máximo de preguerra. En el decenio de posguerra (1921-29) la electrificación en América Latina se desarrolló a gran velocidad, aunque no tanta como en el cuarto de siglo anterior a la guerra.

Las diferencias nacionales son mucho más acusadas que las registradas entre unas y otras etapas por el conjunto de la región. La diversidad es demasiado grande para condensarla en unas pocas líneas, por lo que ceñiré mis comentarios al simple enunciado de las trayectorias nacionales que más se apartan del patrón general ${ }^{48}$. Los casos de mayor éxito son Argentina y Chile, que muestran un dinamismo claramente superior al resto, salvo en el período bélico. República Dominicana es un caso de éxito un tanto dudoso, emparejado con Cuba en su singular evolución durante los tres primeros decenios del siglo XX. Colombia, como Venezuela —en menor medida- y Ecuador - aún en menor medida- sobresale gracias al empuje logrado desde los años previos a la contienda. En el polo opuesto hallamos Haití, algunos países centroamericanos (El Salvador y Guatemala) y Brasil, lo cual no puede dejar de sorprendernos. No resulta evidente la razón del atraso eléctrico de los dos primeros con respecto a Honduras y Nicaragua, aunque sí es fácilmente comprensible que por delante de todos ellos se situara Costa Rica, dado su nivel de prosperidad económica relativa en la región centroamericana. En el caso del gigante sudamericano, el lento avance de la última década del siglo XIX y el retroceso durante la Gran Guerra, aguaron tal vez en exceso el balance global. Si fijamos la atención en el período de mayor esplendor, y más prometedor (1901-1913), en las posiciones más destacadas figuraron Chile, Brasil, Uruguay y Argentina. En el segundo gran brote electrificador (1921-1929), se aupó a la cabecera de los más veloces un puñado de países atrasados, como Venezuela, Ecuador, Haití, Guatemala, El Salvador y Nicaragua, además de algunos de los países de mayor desarrollo eléctrico: Costa Rica, Argentina y Uruguay. Seguramente resultaría extraño

48 Haciendo abstracción de Bolivia y Paraguay, además de Panamá (ni siquiera presente en el cuadro), puesto que su evolución está distorsionada, al menos en las dos primeras décadas, por una muy notable infravaloración de sus importaciones por parte de G-3 (sobrevaloración extrema, en el caso de Panamá). 
terminar esta apresurada lectura del cuadro 6 sin hacer alusión a dos grandes repúblicas, México y Perú. Si no han sido mencionadas hasta ahora es porque pasan desapercibidas. La evolución de la primera es de bajo perfil, lo cual no encaja bien con lo que se desprende de la historiografía, sin duda porque ésta ha contemplado, y enfatizado, la electrificación de México fuera de su contexto regional. Perú también participó discretamente en las dos fases de mayor aceleración en la carrera electrificadora.

\section{EL NIVEL DE DESARROLLO ELÉCTRICO LATINOAMERICANO EN EL CONTEXTO INTERNACIONAL}

Los resultados presentados en el apartado anterior deben ser comparados con los referentes a otras naciones, en particular las más avanzadas económicamente, con vistas a hacer un balance, forzosamente tentativo, sobre los logros de la electrificación en Latinoamérica. En esta comparación tiene especial interés verificar si se cumplió o no la hipótesis gerschenkroniana.

El contraste debe hacerse, en primer lugar, en términos de la producción de electricidad por habitante, que además de constituir la medida básica del grado de desarrollo eléctrico es la única variable sobre la cual existe información suficientemente abundante referida a los años en torno a $1930^{49}$. El gráfico 2 muestra los resultados de la comparación con un amplio grupo de países, tanto desarrollados como subdesarrollados.

Los logros de América Latina se revelan relativamente modestos al contemplarlos a la luz de la posición ocupada por la mayoría de las naciones occidentales. La producción eléctrica latinoamericana $(65 \mathrm{kWh}$ por habitante $\left.{ }^{50}\right)$ representaba en esa fecha tan sólo el 11 por cien de la producción de un grupo de 17 países occidentales. Todos los miembros de la comunidad latinoamericana estaban muy por debajo del nivel de dicho grupo. Cabe matizar que en el mismo pesan los registros récord de las naciones excepcionalmente bien dotadas de recursos hidroeléctricos (Noruega, Canadá, Suiza) o de desarrollo muy singular (Estados Unidos). Por otro lado, es de destacar que las naciones latinoamericanas más avanzadas (Cuba, Chile, Argentina) se situaban por encima de las economías europeas de industrialización tardía, como España, Portugal, Grecia, Hungría o Rumania. E incluso las más retrasadas de la comunidad latinoamericana, con excepción

\footnotetext{
49 Como he señalado, no es así en el caso de América Latina. En los numerosos casos en que se desconoce la producción, la he estimado a partir de la capacidad instalada en 1930 (v. cuadro 4), aplicando un factor de carga del 25 por ciento. Este factor (2.190 horas anuales) parece razonable porque es la media de los casos nacionales conocidos y es aproximadamente coincidente con otros indicios, aunque, por supuesto, los márgenes de error son amplios.

50 CEPAL (1956, p. 27) calcula un consumo por habitante de $72 \mathrm{kWh}$ en el año 1929. Creo que su estimación es más azarosa que la mía para algunos países con muy escasa información. De todos modos, aunque aceptáramos como válida la cifra propuesta por CEPAL, la comparación con los países más avanzados conduciría a las mismas conclusiones.
} 


\section{GRÁFICO 2}

PRODUCCIÓN DE ELECTRICIDAD POR HABITANTE EN 1930 Kwh

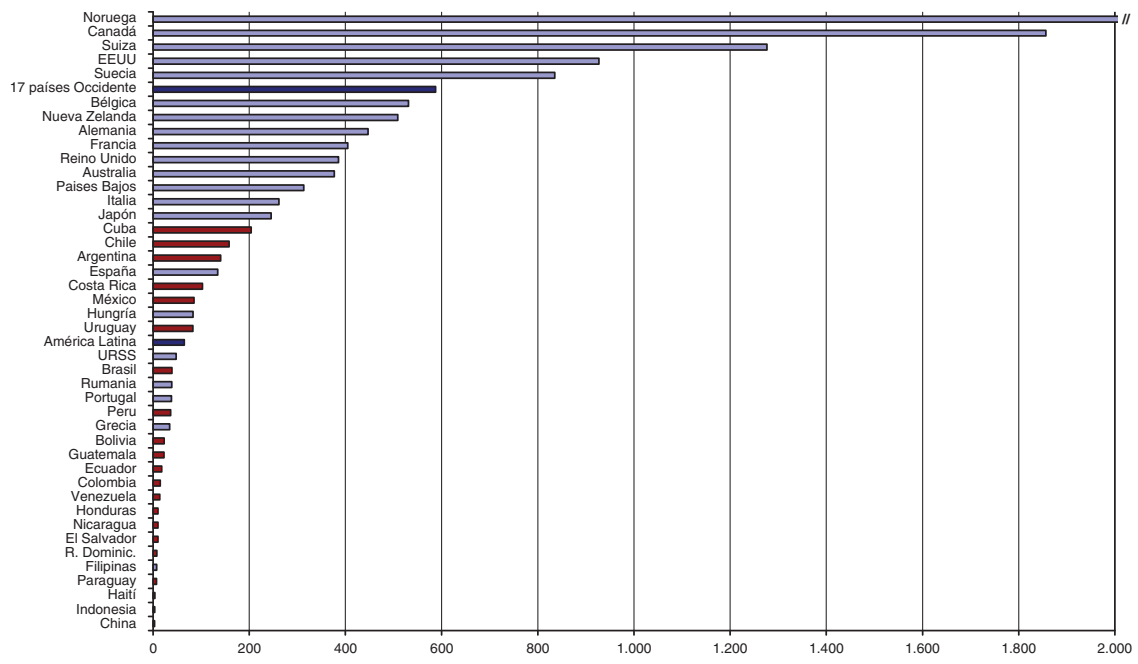

Fuentes: Mitchell (2003a) (2003b) y (2007), y, para América Latina cuadro 1. Las cifras de población proceden de Angus Maddison, 〈http://www.ggdc.net/maddison. Statistics on World Population. GDP and Per Capita GDP. 1-2006 AD (Last update: 10 October 2009)〉

de Haití y Paraguay, tenían un nivel de desarrollo eléctrico superior al de las naciones de Asia (Japón aparte), y también, con toda seguridad, de África —no recogidas en el gráfico por las incertidumbres sobre la magnitud de su población. En definitiva, el primer balance del proceso de electrificación de América Latina lleva a extraer una conclusión que está a medio camino entre el optimismo y el pesimismo. Lo primero se fundamenta en que se situaba en una posición de Segundo Mundo, por detrás de las economías desarrolladas del Primer Mundo pero por delante de aquellas que formaban el Tercero (Asia y África). Por otra parte, los datos no invitan a sacar una conclusión optimista. El nivel de desarrollo eléctrico al que llegó América Latina en 1930, Estados Unidos ya lo había alcanzado en 1901, Suecia en 1908, Alemania en 1909, Reino Unido en 1914, Italia en 1915 y Francia en 1917. En otras palabras, Rippy (1947) no estaba en lo cierto pero no iba completamente desencaminado. La brecha con los países pioneros era mayor al final de la revolución eléctrica que en su inicio.

El gráfico comentado deja en el aire una pregunta fundamental: ¿el nivel de electrificación de los países latinoamericanos era relativamente bajo porque su nivel de desarrollo económico no consentía que fuera más elevado? El gráfico 3 aporta una primera respuesta a este interrogante esencial, a la vez que aporta nueva evidencia para validar la hipótesis gerschenkroniana 


\section{GRÁFICO 3}

PRODUCCIÓN DE ELECTRICIDAD Y NIVEL DE RENTA EN DIVERSOS PAÍSES, 1929-1930

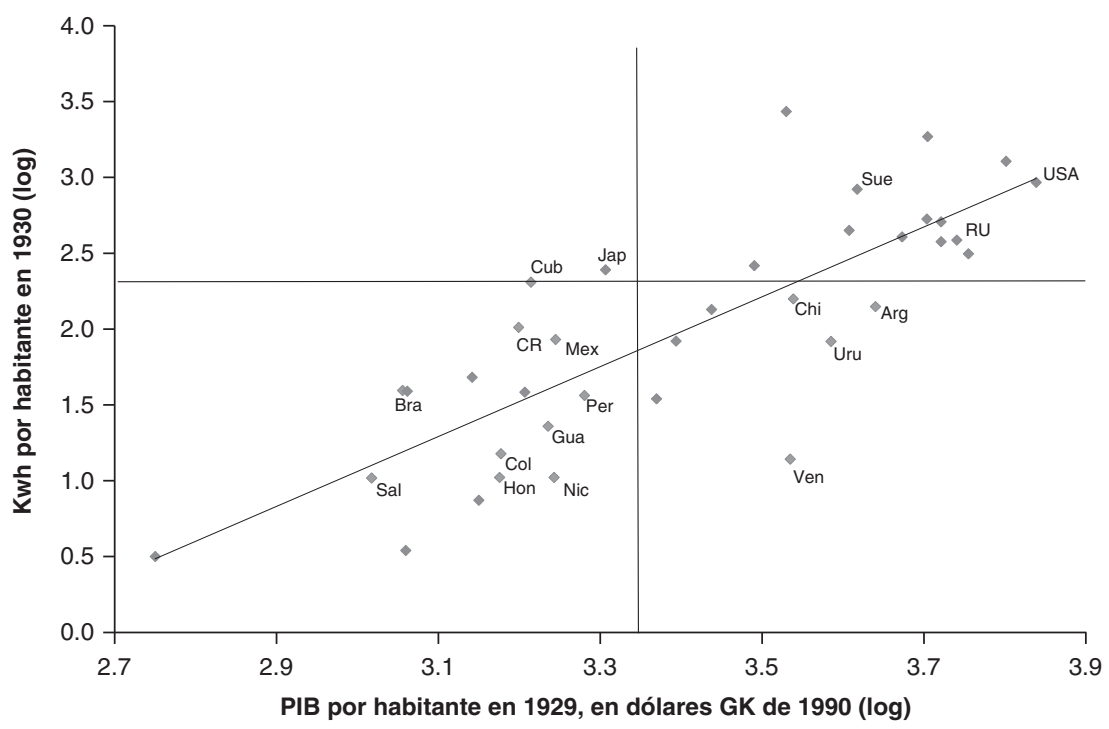

Fuentes: a partir de cuadro 4 (v. texto) y Maddison (v. gráfico 2)

defendida por algunos autores sobre la electricidad en tanto que tecnología de aplicación general.

En el gráfico se aprecia con claridad que la mayoría de las naciones latinoamericanas representadas (14) se emplazan en el cuadrante inferior, es decir, se caracterizan por tener un nivel de PIB y de consumo eléctrico (producción) por habitante inferior a la media ponderada de la muestra de países $^{51}$. Únicamente Argentina, Uruguay, Chile y Venezuela habían alcanzado un grado de desarrollo económico (PIB per cápita) superior al del promedio de esa amplia y variada comunidad de naciones, y solamente Cuba había llegado a tener una producción eléctrica per cápita pareja a la del promedio de esa comunidad. Pero lo más revelador del gráfico no es eso, sino el hecho de que las repúblicas latinoamericanas tienden a emplazarse por debajo de la línea de regresión de las series; esto es, tienden a tener un grado

51 Los países representados son los mismos que figuran en el gráfico 2, salvo Bolivia, Ecuador, Haití, Paraguay y República Dominicana, que han debido excluirse al no disponer del dato de PIB. Las líneas vertical y horizontal corresponden, respectivamente, al PIB por habitante medio ponderado y a la producción eléctrica por habitante media ponderada. 
de electrificación inferior al que les correspondería según su PIB por habitante. Las excepciones - Brasil, Costa Rica, México y Cuba- no pueden ocultar que el patrón normal de la región es el retraso en el proceso de electrificación. Un patrón que halla su contrapunto en la trayectoria de países de industrialización tardía pero acelerada, como Japón y Suecia.

\section{CONSIDERACIONES FINALES}

América Latina asistió puntualmente al nacimiento de la era de la electricidad; al menos así lo hicieron las naciones más avanzadas de la región, e incluso otras que no lo eran. En los años 1880 se introdujo el alumbrado eléctrico en las principales ciudades, generalmente a iniciativa de empresarios locales. Allá donde existía una actividad minera relevante no tardaron en aparecer motores eléctricos aplicados al bombeo de agua, al acarreo y trituración de los minerales y a otras labores. Las propias empresas mineras a menudo abastecieron de fluido eléctrico a las poblaciones vecinas. Unos años más tarde, en el cambio de siglo, comenzaron a circular tranvías eléctricos por las urbes más dinámicas, casi al mismo tiempo que lo hacían en Europa. Con el nuevo siglo, las industrias fueron dotándose de electricidad no ya para iluminar las instalaciones sino para mover la maquinaria. La industria fabril de las economías más desarrolladas (Argentina, Chile, Uruguay), o de aquellas que tenían potentes distritos industriales (Brasil), siguió la estela trazada por sus homólogas de Estados Unidos y Europa en la transición de la tecnología de la máquina de vapor a la del motor eléctrico.

Sin embargo, el consumo de electricidad por habitante seguía siendo bajo transcurrido medio siglo desde los inicios de la electrificación, cuando puede decirse que la revolución eléctrica ya había hecho su curso, según Jovanovic y Rousseau (2005, p. 1.195). Solamente Cuba, Chile, Argentina, Costa Rica, México y Uruguay, por este orden, habían alcanzado unos niveles de consumo análogos a los de las economías europeas de industrialización tardía. Los restantes, salvo Brasil y Perú, hacían un uso de la electricidad extremadamente limitado, apenas mayor al de los países asiáticos (Japón aparte). A diferencia de Japón, Suecia y otras economías de industrialización tardía pero acelerada, los países latinoamericanos no fueron capaces de llevar a cabo con rapidez su proceso de electrificación, sacando provecho de la posibilidad de incorporar una tecnología de aplicación general desarrollada por las economías líderes. En definitiva, la electrificación latinoamericana no se ajustó a la hipótesis gerschenkroniana.

\section{FUENTES Y BIBLIOGRAFÍA}

A energia elétrica no Brasil. Da primeira lâmpada à Eletrobrás (1977): Rio de Janeiro: Biblioteca do Exército Editora. 
Altshuler, José (1998): «Impacto social y espacial de las redes eléctricas en Cuba». Scripta Nova (18), pp. 1-18.

Altshuler, José y González, Miguel (1997): Una luz que llegó para quedarse. Comienzos del alumbrado eléctrico y su introducción en Cuba. La Habana: Editorial Científico-Técnica.

Argentina. Comisión Nacional (1917): Tercer censo nacional. Levantado el $1^{\circ}$ de junio de 1914. Tomo VII: Censo de industrias, y Tomo X: Valores mobiliarios y estadísticas diversas. Buenos Aires: CN.

Argentina. Dirección General de Estadística de la Nación (1939): Estadística industrial de la República Argentina correspondiente al año 1937. Buenos Aires: DGE.

Armstrong, Christopher y Nelles, H. V. (1988): Southern Exposure. Canadian Promoters in Latin America and the Caribbean 1896-1930. Toronto: University of Toronto Press.

Baily, Martin y Robert J. Gordon (1988): "The Productivity Slowdown, Measuremente Issues, and the Explosion of Computer Power». Brookings Papers on Economic Activity (2), pp. 347-420.

Bartolomé, Isabel (2007): La industria eléctrica en España (1890-1936). Madrid: Banco de España.

Bradley, J. R. (1931): Fuel and Power in Latin America. U.S. Department of Commerce. Washington: Government Printing Office.

Brasil. Ministerio da Agricultura (1935): Utilisação de energia electrica no Brasil. Boletim n. 1. Rio de Janeiro: Departamento Nacional da Produção Mineral.

Brasil. Officinas da Estatística Commercial (varios años): Commercio exterior do Brasil. Rio de Janeiro: Directoria de Estatística Comercial.

Bresnahan, Thimothy y Manuel Trajtenberg (1995): «General purpose technologies: 'Engines of growth'?». Journal of Econometrics 65, pp. 83-108.

Bright, ARTHUR (1949): The Electric-Lamp Industry. Technological Change and Economic Development from 1800 to 1947. Nueva York: Macmillan.

Broder, Albert (1987): «The Multinationalisation of the French Electrical Industry 1880-1914: Dependence and its Causes», en P. Hertner y G. JonEs (eds), Multinationals: Theory and History. Aldershot: Gower, pp. 169-191.

ByatT, I.C.R. (1979): The British Electrical Industry 1875-1914. The economic returns to a new technology. Oxford: Clarendon Press.

CAmilo Rodríguez, JuAn, et al. (1999): Historia de la Empresa de Energía de Bogotá (1896-1927). Bogotá: Empresa de Energía de Bogotá.

CARlson, W. Bernard (1991): Innovation as a social process. Elihu Thomson and the rise of General Electric, 1870-1900. Cambridge (MA): Cambridge University Press.

Carson, James S. (1946): "The Power Industry», en L. J. Hughlett (ed.), Industrialization of Latin America. Nueva York: McGraw-Hill, pp. 319-345.

CARTER, Susan B. et al. (eds) (2005): Historical Statistics of the United States: earliest times to the present (millennial edition), 5 vols. New York: Cambridge University Press. 
Centro Industrial do Brasil (1909): O Brasil. Suas riquezas naturaes. Suas industrias. Vol. III: Industria de Transportes. Industria fabril. S.l.

Chile. Dirección General de Estadística (1931): Estadística anual. Año 1929. Vol. IV: Minería e Industria. Santiago de Chile: Imprenta Universo.

Chile. Oficina Central de Estadística (1921): Anuario estadístico de la república de Chile. Año 1920. Vol. VIII: Industrias. Santiago de Chile: Imprenta Universo.

Comisión de Integración Eléctrica Regional (CIER) (1989): 25 años. Historia, funcionamiento y realizaciones de la Comisión. Reseñas históricas de los servicios públicos de electricidad de los países miembros. Montevideo: CIER.

COMIsIón Económica PARA AmÉRICA LATINA (CEPAL) (1956): La energía en América Latina. México, D.F.: Cepal.

Crafts, Nicholas (2004): «Steam as a General Purpose Technology: A Growth Accounting Perspective». The Economic Journal 114 (april), pp. 338-351.

David, Paul (1990): «The Dynamo and the Computer: An Historical Perspective on the Modern Productivity Paradox». American Economic Review 80 (2), pp. 355-361.

David, Paul (1991): "Computer and dynamo. The modern productivity paradox in a not-too-distant mirror», en OECD (ed.), Technology and Productivity. The Challenge for Economic Policy, OECD: Paris, pp. 315-347.

David, Paul A. y Gavin Wright (1999): Early Twentieth Century Productivity Growth Dynamics: An Inquiry into the Economic History of 'Our Ignorance'. Discussion Papers in Economic and Social History $n^{\circ} 33$, University of Oxford.

David, Paul A. y Gavin Wright (2003): «General Purpose Technologies and Surges in Productivity. Historical Reflections on the Future of the ICT Revolution", en Paul A. David y Mark Thomas (eds), The Economic Future in Historical Perspectives. Oxford: Oxford University Press, pp. 135-166.

De la Garza Toledo, EnRique, et al. (1994): Historia de la industria eléctrica en México, 2 tomos. México: UNAM.

De la Pedraja Tomán, René (1985): Historia de la energía en Colombia, 15371930. Bogotá: El Áncora editores.

Devine, Warren D. (1983): «From Shafts to Wires: Historical Perspective on Electrification». Journal of Economic History 43 (2), pp. 347-372.

Directoria Geral do Brazil (1927): Recensamento do Brazil. Realizado em 1 de Setembre de 1920. Vol. V: Industria. Rio de Janeiro: DGB.

DuBoff, Richard B. (1979): Electric Power in American Manufacturing, 18891958. Nueva York: Arno Press.

Duffy, Michael C. (2003): Electric Railways 1880-1990. Londres: The Institution of Electrical Engineers.

Feinstein, Charles (1988): «National Statistics, 1760-1920», en C. H. Feinstein y S. Pollard (eds), Studies in Capital Formation in the United Kingdom, 1750-1920. Oxford: Clarendon. 
Frank, Florian (1999): "Que se haga la luz», en J. A. Rodríguez (compilador), Alemanes en las regiones equinocciales. Caracas: Alfadil Ediciones, pp. 244-262.

Galarza, Ernesto (1941): La industria eléctrica en México. México D.F.: Fondo de Cultura Económica.

Halsey, Frederic M. (1918): Investments in Latin America and the British West Indies. U.S. Department of Commerce. Special Agent Series $n^{0} 169$. Washington: Government Printing Office.

Hausman, William J.; Hertner, Peter y Wilkins, Mira (2008): Global Electrification. Multinational Enterprise and International Finance in the History of Light and Power, 1878-2007. Cambridge: Cambridge University Press.

Helpman, Elhanan y Manuel Trajtenberg (1998a): "A time to sow and a time to reap: growth based on general purpose technologies», en E. Helpman (ed.), General Purpose Technologies and Economic Growth. Cambridge: MIT Press, pp. 55-83.

Helpman, Elhanan y Manuel Trajtenberg (1998b): «Diffusion of general purpose technologies», en E. Helpman (ed), General Purpose Technologies and Economic Growth. Cambridge: MIT Press, pp. 85-119.

Herken, Juan Carlos (1984): Ferrocarriles, conspiraciones y negocios en El Paraguay, 1910-1914. Asunción: Arte Nuevo editores.

Hertner, Peter (1987): «German Multinational Enterprise before 1914», en P. Hertner y G. Jones (eds), Multinationals: Theory and History. Aldershot: Gower, pp. 113-134.

Hertner, Peter (1989): «Financial strategies and adaptation to foreign markets: the German electro-technical industry and its multinational activities: 1890s to 1939», en A. Teichova, M. Lévy-Leboyer y H. Nussbaum (eds), Multinational enterprise in historical perspective. Cambridge/París: Cambridge University Press/Éditions de la Maison des Sciences de l'Home, pp. 145-159.

Hughes, Thomas P. (1983): Networks of Power: Electrification in Western Society, 1880-1930. Baltimore: John Hopkins University Press.

Instituto Brasileiro de Geografia e Estatística. Serviço Nacional de Recenseamento (1954): O censo industrial das nações americanas. Rio de Janeiro: I.B.G.E.

Jalava, Jukka y Matti Pohjola (2008): «The roles of electricity and ICT in economic growth: Case Finland». Explorations in Economic History 45, pp. 270-287.

Jovanovic, Boyan y Peter L. Rousseau (2005): «General Purpose Technologies», en P. Agion y S. N. Durlauf (eds), Handbook of Economic Growth, Vol 1B, pp. 1181-1223.

Landes, David (1969): The unbound Prometheus. Cambridge: Cambridge University Press.

Lieh, Reinhard y Leidenberger, G. (2006): «El paso de una free-standing company a una empresa pública: Mexican Light and Power y Mexico 
Tramways, 1902-1960», en S. Kuntz y H. Pietschmann (eds), México y la economía atlántica (siglos XVIII-XX). México: El Colegio de México, pp. 269-309.

Lipsey, Richard, G.; Cliff, Bekar y Kenneth Carlaw (1998): «What Requires Explanation?», en E. Helpman (ed.), General Purpose Technologies and Economic Growth. Cambridge: MIT Press, pp. 15-54.

Lipsey, Richard, G.; Kenneth, I. Carlaw y Clifford, T. Bekar (2005): Economic Transformations. General Purpose Technologies and Long-Term Economic Growth. Oxford: Oxford University Press.

Machefert-Tassin, Yves, Nouvion, Fernand y Woimant, Jean (1980): Histoire de la traction électrique. Tome 1: des origins à 1940. París: La Vie du Rail.

McDowall, Duncan (1988): The Light. Brazilian Traction, Light and Power Company Limited 1889-1945. Toronto: University of Toronto Press.

México. Dirección Nacional de Irrigación (1931): La industria eléctrica en México. Estudios estadísticos preliminares. México D.F.: Editorial Cultura.

México. Dirección General de Estadística (1935): Primer censo industrial de 1930. vol. III: Resúmenes generales por industrias. México D.F.: DGE.

McKay, John P. (1976): Tramways and Trolleys. The Rise of Urban Mass Transport in Europe. Princeton (NJ): Princeton University Press.

Mitchell, B.R. (2003a): International Historical Statistics: Africa, Asia and Oceania 1750-2000. Nueva York: Palgrave Macmillan.

Mitchell, B.R. (2003b): International Historical Statistics: Europe 1750-2000. Nueva York: Palgrave Macmillan.

Mitchell, B.R. (2007a): International Historical Statistics: the Americas 17502005. Nueva York: Palgrave Macmillan.

Mokyr, Joel (1990): The lever of riches. New York: Oxford University Press.

Mota, Francisco M. (1982): Por primera vez en Cuba. La Habana: Editorial Gente Nueva.

Naciones, Unidas (1962): Estudios sobre la electricidad en América Latina. Vol. I: Informes y documentos. México, D.F.: NU.

Oliner, Stephen D. y Daniel, E. Sichel (2000): «The Resurgence of Growth in the Late 1990s: Is Information Technology the Story?». Journal of Economic Perspectives 14 (4), pp. 3-22.

Oulton, Nicholas (2002): «ICT and Productivity Growth in the United Kingdom». Oxford Review of Economic Policy 18 (3), pp. 363-379.

Passer, Harold, C. (1953): The Electrical Manufacture 1875-1900. A Study in Competition, Entrepreneurship, Technical Change, and Economic Growth. Cambridge (MA): Harvard University Press.

RIPPY, J. FRED (1947): Latin America and the Industrial Age. Nueva York: G.P. Putnam's Sons.

RIPPY, J. FRED (1948): «German Investments in Latin America». The Journal of Business of the University of Chicago 21 (2), pp. 63-73.

Ristuccia, Cristiano A. y Solomos Solomou (2002): Electricity diffusion and Trend Acceleration in Inter-War Manufacturing Productivity. Working 
paper of Department of Applied Economics, University of Cambridge, Cambridge.

Rohrmoser, G. (1986): «Centenario de la electricidad en Costa Rica». Revista de Filosofía de la Universidad de Costa Rica (24), pp. 117-118.

Rosenberg, Nathan (1982): Inside the black box: Technology and economics. Cambridge: Cambridge University Press.

SchURR, S. H. et al. (1990): Electricity in the American Economy: Agent of Technological Progress. New York: Greenwood Press.

Segreto, Luciano (1993): «Aspetti e problemi dell'industria elettrica in Europa tra le due guerre», en G. Galasso (a cura), Storia dell'industria elettrica in Italia. Vol. 3: Espansione e oligopolio. 1926-1945. Roma: Laterza.

SiEmens, Georg (1957): History of the House of Siemens. Vol. I: The Era of Free Enterprise. Freiburg/Munich: Karl Alber.

Singer, Charles, et al. (1980): A history of technology. Vol. 5: The late nineteenth century, c. 1850-c.1900. Oxford: Clarendon Press.

Sinopsis estadística y geográfica de la República de Chile en (1906): Santiago de Chile: Imprenta García Valenzuela.

Sмiтн, Philip S. (1917): Electrical goods in Cuba, U.S. Department of Commerce. Bureau of Foreign and Domestic Commerce. Washington: Government Printing Office.

Sмiтh, PhiLIP S. (1918): Electrical goods in Bolivia and Chile, U.S. Bureau of Foreign and Domestic Commerce. Washington: Government Printing Office.

Sмiтн, Philip S. (1919): Electrical goods in Argentina, Uruguay, and Brazil, U.S. Bureau of Foreign and Domestic Commerce. Washington: Government Printing Office.

TAFUnelL, XaVIER (2009a): «La inversión en equipo de transporte de América Latina, 1890-1930: una estimación basada en la demanda de importaciones». Investigaciones de Historia Económica 14, pp. 39-67.

TAFUnell, Xavier (2009b): "Capital Formation in Machinery in Latin America, 1890-1930». Journal of Economic History 69 (4), pp. 928-950.

Tafunell, Xavier y Albert, Carreras (2008): «La América Latina y el Caribe en 1913 y 1925. Enfoque desde las importaciones de bienes de capital». Trimestre Económico 75 (3), pp. 715-753.

United Nations (1987): Energy statistics. Definitions, Units of Measures and Conversion Factors, Studies in Methods. Series F, no 44. Nueva York: U.N.

Uruguay. Dirección General de Estadística (1911): Anuario estadístico de la República Oriental del Uruguay, tomo II, parte III. Montevideo: DGE.

U.S. Department of Commerce (1926): Commerce Yearbook 1926, Vol. II: Foreign Countries. Washington: Government Printing Office.

U.S. Department of Commerce (1927a): Central Lights and Power Plants in the Western Hemisphere with Notes on the Market for Electrical Goods. Washington: Government Printing Office. 
U.S. Department of Commerce (1927b): The Electrical Equipment Market in Chile. Washington: Government Printing Office.

U.S. TARIFF Comission (1945): Mining and Manufacturing Industries in Brazil. Washington: Government Printing Office.

Velasco, Salmón, Lilian Valeria (2007): La fábrica de luz. Historia de la Compañía Boliviana de Energía Eléctrica S.A. - Bolivian Power Company Ltd. La Paz: Compañía Boliviana de Energía Eléctrica S.A.

Villalobos, Sergio (dir.) (1990): Historia de la ingeniería en Chile. Santiago de Chile: Instituto de Ingenieros de Chile/Hachete.

Weiner, Sigfrid Von y Goetzeler, Herbert (1984): The Siemens Company. Its Historical Role in the Progress of Electrical Engineering 1847-1980. Berlín: Siemens Aktiengesellschaft (segunda edición).

WiLKINS, Mira (1974): The Maturing of Multinational Enterprise: American Business Abroad from 1914 to 1970. Cambridge (MA): Harvard University Press.

Young, George, F. W. (1995): «Los bancos alemanes y la inversión directa alemana en América Latina, 1880-1930», en C. MARICHAL (COOR.), Las inversiones extranjeas en América Latina, 1850-1930. Nuevos debates y problemas en historia económica comparada. México D.F.: El Colegio de México/Fondo de Cultura Económica, pp. 96-124. 